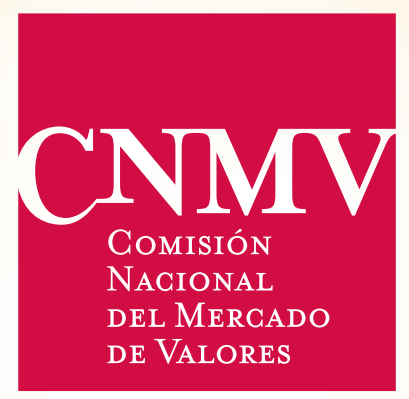

\title{
Interest Rates and Credit Risk
}

Carlos González-Aguado

CNMV

Javier Suárez

CEMFI and CEPR

Documentos de Trabajo No 46 



\section{Interest Rates and Credit Risk}

Carlos González-Aguado

CNMV

Javier Suárez

CEMFI and CEPR

\section{Documentos de Trabajo}

$\mathrm{N}^{\circ} 46$

Junio/June 2011

We would like to thank Óscar Arce, Arturo Bris, Andrea Caggese, Rafael Repullo, Enrique Sentana, David Webb and seminar participants at the 2009 European Economic Association Meeting, the 2010 World Congress of the Econometric Society, Banco de España, CEMFI, CNMV, European Central Bank, Instituto de Empresa, Norges Bank, Swiss National Bank, Universidad Carlos III, Universidad de Navarra, and the XVIII Foro de Finanzas for helpful comments and suggestions. Contact e-mails: cgaguado@cnmv.es, suarez@cemfi.es. 
Carlos González-Aguado, Research, Statistics and Publications Department, CNMV.

Javier Suárez, CEMFI and CEPR.

The opinions in this Working Paper are the sole responsibility of the authors and they do not necessarily coincide with those of the CNMV.

The CNMV publishes this Working Paper Series to spread research in order to contribute to the best knowledge of the stock markets and their regulation.

The CNMV distributes its reports and publications via the Internet at www.cnmv.es

(C) CNMV. The contents of this publication may be reproduced, subject to attribution.

Carlos González-Aguado, Departamentos de Estudios, Estadísticas y Publicaciones, CNMV.

Javier Suárez, CEMFI y CEPR.

Las opiniones expresadas en este documento reflejan exclusivamente el criterio de los autores y no deben ser atribuidas a la Comisión Nacional del Mercado de Valores.

La Comisión Nacional del Mercado de Valores, al publicar esta serie, pretende facilitar la difusión de estudios que contribuyan al mejor conocimiento de los mercados de valores y su regulación.

La Comisión Nacional del Mercado de Valores difunde la mayoría de sus publicaciones a través de la red Internet en la dirección www.cnmv.es

(C) CNMV. Se autoriza la reproducción de los contenidos de esta publicación siempre que se mencione su procedencia.

ISSN (edición impresa): 2172-6337

ISSN (edición electrónica): 2172-7147

Depósito Legal: BI-2910-2010

Maqueta e imprime: Composiciones Rali, S.A. 


\section{Abstract}

This paper explores the effects of shifts in interest rates on corporate leverage and default. We develop a dynamic model in which the relationship between firms and their outside financiers is affected by a moral hazard problem and entrepreneurs' initial wealth is scarce. The endogenous link between leverage and default risk comes from the lower incentives of overindebted entrepreneurs to guarantee the survival of their firms. Firms start up with leverage typically higher than some statecontingent target leverage ratio, and adjust gradually to it through earnings retention. The dynamic response of leverage and default to cuts and rises in interest rates is both asymmetric (since it is easier to adjust to a higher target leverage than to a lower one) and heterogeneously distributed across firms (since interest rates affect the burden of outstanding leverage, which differs across firms). We find that both interest rate rises and interest rate cuts increase the aggregate default rate in the short-run. Instead, higher rates produce lower default rates in the longer run since they induce lower target leverage across all firms. These results help rationalize some of the empirical evidence regarding the so-called risk-taking channel of monetary policy.

Keywords: interest rates, short-term debt, search for yield, credit risk, firm dynamics.

JEL Classification: G32, G33, E52. 



\section{Table of contents}

The model

$\begin{array}{llr}2.1 & \text { Model ingredients } & 15\end{array}$

\begin{tabular}{lll}
\hline 2.2 & Discussion of the ingredients & 16
\end{tabular}

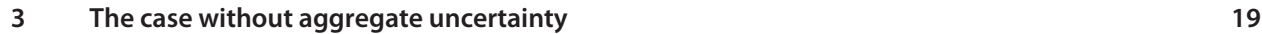

\begin{tabular}{llr}
\hline 3.1 & Firms' dynamic financing problem & 19
\end{tabular}

\begin{tabular}{lll}
\hline $3.2 \quad$ Implied dynamics & 21
\end{tabular}

$\begin{array}{ll}\text { 3.3 Comparative statics and dynamics } & 23\end{array}$

\begin{tabular}{ll}
\hline .4 & Equilibrium entry
\end{tabular}

$\begin{array}{llr}4 & \text { The case with aggregate uncertainty } & 27\end{array}$

\begin{tabular}{llr}
\hline 4.1 & Equilibrium conditions & 27
\end{tabular}

\begin{tabular}{lll}
\hline 4.2 Parameterization & 29
\end{tabular}

$5 \quad$ Macroprudential implications $\quad 37$

6 Conclusions 



\section{Index of figures}

\begin{tabular}{llr} 
FIGURE 1 & Phase diagram with a stable steady state & 22 \\
\hline FIGURE 2 & Effects of unexpected once-and for-all changes in $r$ & 25 \\
\hline FIGURE 3 & Leverage dynamics with aggregate uncertainty & 28 \\
\hline FIGURE 4 & Evolution of leverage and default along firms' life & 33 \\
\hline FIGURE 5 & Individual effects of shifts in the interest rate & 33 \\
\hline FIGURE 6 & Aggregate effects of changes in the interest rate & 34 \\
\hline FIGURE 7 & Aggregate effects under alterantive interest rate dynamics & 35
\end{tabular}

\section{Index of tables}

TABLE 1 Parameter values 30 



\section{Introduction}

The experience surrounding the Great Recession of 2008-2009 has extended the idea that long periods of low (real) interest rates may have a cost in terms of financial stability. Many observers believe that keeping interest rates too low for too long - as it happened during the Greenspan era - contributed to aggregate risk-taking in the years leading to the crisis. Concepts such as "search for yield" (Rajan, 2005) and "risk taking channel of monetary policy" (Borio and Zhu, 2008) have been coined to refer to the phenomenon whereby financial institutions, in particular, might have responded to low real interest rates by accepting higher risk exposures. One manifestation of such exposures would be the unprecedented pre-crisis leverage of the private non-financial sector, which surely contributed to the high default rates observed after things turned wrong.

Formal empirical evidence on these issues is relatively recent and suggests that the underlying phenomena are quite complex. In fact one first complexity refers to properly identifying causal relationships, since movements in real interest rates, even when driven by discretionary monetary policy decisions, constitute endogenous reactions to prior or parallel developments in the real and financial sectors. Ioannidou et al. (2010), Jiménez et al. (2010), and Maddaloni and Peydró (2011) provide evidence that reductions in interest rates are followed by a deterioration of lending standards and, with some additional lag, by rises in default rates. ${ }^{1}$ From here it would be tempting to conclude that lowering interest rates increases credit risk, but this would certainly be an over-simplified reading of the evidence. The same studies acknowledge that the effects of shifts in interest rates are typically asymmetric across interest rises and cuts, and operate heterogeneously across firms and non-monotonically over time. Specifically, some evidence supports the view that interest rate rises may increase credit risk in the short run, certainly for the most indebted borrowers, and perhaps at the aggregate level, while the response to interest rate cuts may not be symmetric. ${ }^{2}$ This points to nonlinearities, as well as timing and cross-sectional considerations, of great importance for the design of both traditional monetary policy and the new macroprudential policies commended to authorities such as the Financial Stability Oversight Council and the European Systemic Risk Board.

The objective of this paper is to develop an infinite horizon model of the effects of interest rates shifts on corporate leverage and corporate default. Theoretical work on this topic is scarce, possibly due to the difficulty of putting together corporate

1 See also Altunbas et al. (2009).

2 Jacobson et al. (2008), using data on Swedish firms, find that the short-run effect of (contemporaneous or one-period lagged) interest rates on default rates is positive. In a clinical study, Landier et al. (2011) argue that interest rate rises started in 2004 could have pushed a major US subprime mortgage originator into making riskier loans. 
finance frictions and the root causes of interest rate shifts (monetary policy? shifts in the supply of loanable funds? shifts in intertemporal preferences?). Several corporate finance and banking papers have looked at the issue in essentially static, nonmonetary models that, like we will do, take the shortcut of representing monetary policy as an exogenous shift in investors' opportunity cost of funds (or in the real risk-free interest rate). Examples of this approach go back to Stiglitz and Weiss (1981) and include Mankiw (1986), Williamson (1987), Holmstrom and Tirole (1997), Repullo and Suárez (2000), and Bolton and Freixas (2006). ${ }^{3}$

In macroeconomics, the topic has been mainly examined by the literature on the credit channel of monetary policy. Carlstrom and Fuerst (1997) and Bernanke, Gertler, and Gilchrist (1999) focus on the dynamics of an external financing premium which reflects the deadweight costs of a static costly-state-verification contract - where verification is the model counterpart of default. However, like in the banking papers cited above, firms' financing problems are formulated as essentially static, using an overlapping generations structure. In the credit to the entrepreneurs in Kiyotaki and Moore (1997) and to the banks of Gertler and Kiyotaki (2010), like in many other papers with agents subject to credit constraints, default is an out-of-equilibrium phenomenon.

Our paper fits in the tradition of the relatively recent literature that looks at genuinely dynamic corporate finance problems in an (industry or general) equilibrium setup. In this literature, some papers focus on optimal dynamic financing decisions under given contractual forms (Cooley and Quadrini, 2001, Hennessy and Whited, 2005, Cooley and Quadrini, 2006, Hackbarth et al., 2006, Morellec at al., 2008), while others look at optimal dynamic contracts (Clementi and Hopenhayn, 2006, DeMarzo and Fishman, 2007). Among these papers, only Cooley and Quadrini (2006) consider the effects of shocks to a bank lending rate controlled by the monetary authority in a model where firms access external finance through a sequence of short-term debt contracts. They obtain responses of leverage to rises in lending rates similar to ours (and with similar heterogeneity across more and less financially-constrained firms) but they do not discuss asymmetric responses to interest rate rises and interest rate cuts and their framework delivers no implications for credit risk (since the assumed borrowing constraints are such that default never occurs in equilibrium). ${ }^{4}$

We contribute to the first strand of this literature by allowing for and focusing the attention on the effects of interest rate shocks on credit risk. Our model is characterized by three key features. First, firms obtain outside financing using a sequence of short-term debt contracts. ${ }^{5}$ Second, their relationship with outside financiers is affected by a moral hazard problem like in the static models of Holmstrom and Tirole (1997) and Repullo and Suárez (2000), although the problem in our case involves genuinely dynamic trade-offs. Specifically, in every period, the firm owners (or entrepreneurs) make a continuous unobservable decision on private benefit taking

3 In all these papers, monetary policy has an impact on the amount of credit but not necessarily on credit risk. For example, in Holmstrom and Tirole (1997), the binary-action formulation of the underlying moral hazard problem makes equilibrium default risk equal to one of the parameters of the model.

4 We suspect that the asymmetric response of leverage to interest rate cuts and rises should also be present in their setup, but the paper is silent about this.

5 The assumption regarding the sole use of short-term debt is later relaxed considering situations in which the firm can buy insurance against shifts in interest rates. We show that the main results are robust to this extension. 
that has a continuous (negative) impact on the probability that the firm survives into the next period, providing an endogenous incentive-based link between leverage and default. Third, short-term interest rates, which determine the opportunity cost of funds of the outside financiers, follow a Markov chain. So interest rate shocks are an integral part of the environment and firms make financing decisions knowing that future rates may change.

The model also features endogenous entry and exit. Like in other papers in the literature, we assume that entrepreneurs always discount the future at a higher rate than outside financiers, providing a prima facie case for the outside financing of their firms even in the long-run. ${ }^{6}$ Entering entrepreneurs start up penniless (and hence need debt to undertake their initial investments) but, once their firms are active, they can use earnings to reduce their firms' leverage. Alternatively, they can pay dividends to themselves, but these dividends are immediately consumed and cannot be re-injected into the firm at a later date. Entrepreneurs running non-surviving firms leave the economy forever. Finally, the (costly) entry of novel entrepreneurs prevents the measure of active firms from going to zero.?

The model delivers leverage ratios and default probabilities that are, ceteris paribus, decreasing with firm age. The reason for this is that firms start up with leverage ratios larger than their long-term targets, and can only gradually approach their longterm targets via earnings retention. Firms with excess leverage have lower continuation value and, thus, greater incentives to extract private benefits and put their continuation at risk. Moreover, for the equilibrium levels of leverage, non-surviving firms always default on their debts, producing an intuitive correlation between leverage and credit risk. ${ }^{8}$

We find that, due to the underlying financial frictions, (i) interest rate cuts and interest rate rises have asymmetric effects on leverage and default, (ii) the response to interest rate shifts is heterogeneous across firms, and (iii) interest rate shifts have different implications for leverage and default in the short run and in the longer run. The asymmetries are due to the fact that, due to the need to rely on retained earnings for leverage reductions, it is easier to adjust leverage up (following interest rate cuts) than down (following rises). In fact, for the firms that are above target leverage, a rise in interest rates may imply a temporary increase in leverage and credit risk (due to the extra cost of their outstanding debt). ${ }^{9}$ The heterogeneity in the response of firms to interest rate shifts is relevant because the presence of endogenous exit and entry makes that firms are not equally levered when a shift occurs. Opposite to mature firms, rises in interest rates produces a temporary increase in leverage and default risk among younger firms, whose debt tends to be further away from target

6 Entrepreneurs' larger discounting can be justified as a result of unmodelled tax distortions that favor outside debt financing, or as a reduced-form for the discount for undiversifiable idiosyncratic risk that would emerge if entrepreneurs were risk averse.

7 As a convenient way of capturing congestion (or aggregate decreasing returns to scale) in finding a profitable investment opportunity, we assume that the costs of entry of candidate entrants is increasing in the number of already existing firms.

8 The higher survival rate of older firms is consistent with the evidence in, for example, Evans (1987) or Audretsch (1991).

9 The empirical literature on the effects of monetary policy shocks on real output have also found asymmetries, e.g. Cover (1992), typically attributed to nominal rigidities, e.g. Weise (1999). 
leverage. In contrast, the effects of interest rate cuts are of the same sign for mature and younger firms, although quantitatively more pronounced for the latter since lower rates allow them to speed up convergence to target leverage.

The propagation of the effects of interest rate shifts over time is mainly explained by the fact that interest rate shifts (which are quiet persistent) change firms' leverage target. The shifts typically find many firms in their old leverage target (and the rest converging to it). The strong initial effect dampens away as the adjustment to the new target is completed.

The model produces an endogenous law of motion for the distribution of firms across possible debt levels which can be used to produce consistent measures of aggregate leverage and aggregate default. Under our parameterization of the model (partly chosen with the objective of matching moments produced by the model with those prevailing among US firms), we obtain the somewhat surprising result that both interest rate rises and interest rate cuts produce short-run increases in the default rate. This means that the transitional leverage-increasing effect observed among young firms drives up the aggregate default rate immediately after interest rate rises, while the impact of interest rate cuts is explained by the increase in target leverage across all firms. In the longer run, interest rate rises end up decreasing aggregate leverage and default, while interest rate cuts have the opposite effects.

All in all, the paper provides a rationalization of some of the phenomena that, when empirically documented in the papers like the ones mentioned in the opening paragraphs, tend to be taken as due to "search for yield" incentives among financial institutions, and evidence of a "risk taking channel of monetary policy". Interestingly, our rationalization is based on the dynamic extension of well-known agency-theoretic corporate finance models and does not rely on irrational agents (e.g. Shleifer and Vishny, 2010) or given institutions such as accounting principles, risk-management techniques or compensation practices whose procyclicality explains the effects (e.g. in Adrian and Shin, 2009).

Our analysis may help understand the variety of, often apparently contradictory or paradoxical, empirical results about the link between monetary policy and credit risk. Specifically, the asymmetries and sources of heterogeneity in the response to interest rate shifts that we identify are consistent with the ambiguous or mixed signs of the aggregate effects found using linear regression models. It points to the explicit consideration of asymmetries, nonlinearities, cross-sectional heterogeneity and aggregation---issues already explored in some but not all papers on the topic---as a fruitful strategy for future research.

The paper is organized as follows. Section sec:model describes the model. Section sec:no-uncertainty studies the case without aggregate uncertainty regarding interest rates, for which we can obtain analytical results. Section sec:uncertainty extends the characterization of equilibrium to the case with aggregate uncertainty regarding interest rates, presents the parameterization used in the numerical analysis, and discusses the results regarding the effects of interest rate shifts. Section sec:discussion briefly elaborates on the macroprudential implications of the analysis. Section sec:conclusions concludes. 


\section{The model}

We consider an infinite-horizon discrete-time economy in which dates are indexed by $t=0,1, \ldots$ and there are two classes of risk-neutral agents, entrepreneurs and financiers.

\subsection{Model ingredients}

There are many competitive financiers with deep pockets and the opportunity of investing their funds in a reference short-term risk-free asset that yields a rate of return $r_{t}$ during the period between dates $t$ and $t+1$. This rate follows a Markov chain with two possible values $r^{L}$ and $r^{H}$ with $r^{L} \leq r^{H}$ and a time-invariant transition probability matrix $\Pi=\left\{\pi_{i j}\right\}_{i=L, H}^{j=L, H}$ where $\pi_{i j}=\operatorname{Pr}\left[r_{t+1}=\mathrm{r}^{j} \mid r_{t}=r^{i}\right] . r_{t}$ realizes at the beginning of each period.

A new cohort of entrepreneurs, made up of a continuum of individuals, is born at each date $t$. Entrepreneurs are potentially infinitely-lived and their time preferences are characterized by a constant per-period discount factor $\beta<1 /\left(1+r^{H}\right)$ so that entrepreneurs have incentives to rely on outside funding even if they are able to self-finance their firms.

Entrepreneurs are born penniless and with a once-in-a-lifetime investment opportunity. By incurring a non-pecuniary idiosyncratic entry cost $\theta$ at date $t$, each novel entrepreneur can find a project whose development gives rise to a new firm. The distribution of $\theta$ across novel entrepreneurs is described by a cumulative distribution (or measure) function $F\left(\theta, n_{t}\right)$ which depends negatively on the measure $n_{t}$ of firms operating in the economy at date $t$. The fact that the costs of finding a project are increasing (in the sense of first order stochastic dominance) in the measure of active firms, provides an equilibrating mechanism for the entry of new firms (and for the determination of $n_{t}$ ).

Each project requires an unpostponable initial investment normalized to one and the continued management by the founding entrepreneur. Each project operative at date $t$ has a probability $p_{t}$ of remaining productive at date $t+1$. A productive project generates a positive cash flow $y$ per period. With probability $1-p_{t}$ the project fails, in which case it yields a liquidation cash flow $L$ (out of the residual value of the initial investment) and disappears forever. The discretionary liquidation of the project at any date also yields $L$.

Importantly, the continuation probability $p_{t}$ is determined by an unobservable decision of the entrepreneur which also affects the flow of private benefits $u\left(p_{t}\right)$ that he extracts from his project in between dates $t$ and $t+1$. For notational simplicity, we 
assume those private benefits to accrue at $t+1$ independently of whether the project fails. We assume $u(\cdot)$ to be decreasing and concave, and with enough curvature to guarantee interior solutions for $p_{t}{ }^{10}$ Thus, entrepreneurs can appropriate a larger (but marginally decreasing) flow of private benefits by lowering their probability of continuation. This creates a moral hazard problem in the relationship between entrepreneurs and financiers.

Insofar as a project remains productive, the entrepreneur can raise outside financing issuing short-term debt. Such debt is described as a pair $\left(b_{t^{\prime}} \mathrm{R}_{t+1}\right)$ specifying the amount lent by the financiers, $b_{t}$, and a repayment obligation from the entrepreneur to the financiers after one period, $\mathrm{R}_{t+1}$. At $t+1$, if the firm fails or is unable to obtain the funds necessary to pay $R_{t+1}$, then the project is liquidated and financiers are paid the whole liquidation value $L .{ }^{11}$ Otherwise, the firm decides on its financing for the next period subject to its uses and sources of funds equality:

$$
c_{t}+R_{t}=y+b_{t^{\prime}}
$$

where $c_{t}$ denotes the entrepreneur's dividend. We impose $c_{t} \geq 0$ to reflect that the entrepreneur cannot recapitalize the firm using his own outside wealth.

\subsection{Discussion of the ingredients}

We have described $r_{t}$ as the return of a short-term risk-free investment alternative available to financiers, but other interpretations are possible. It may capture a deeper time-preference parameter, an international risk-free rate relevant for a "small open economy", or a convolution of exogenous factors that determine financiers' required expected rate of return. ${ }^{12} \mathrm{~A} n$-state Markov process is a simple way to capture uncertainty regarding the evolution of this variable. The $n=2$ case facilitates computations and is useful to fix intuitions.

The assumption that entrepreneurs have larger discount rates than their financiers is common in the literature (e.g. Cooley and Quadrini, 2001). It provides a prima facie case for entrepreneurs to keep relying on external financing. If outside financing takes the form of debt and inside financing takes the form of equity (as it is typically the case in practice and several corporate finance theories have justified), one might interpret this assumption as a result of net tax advantages of debt financ-

10 A sufficient condition to guarantee this would be having $u^{\prime}(0)=0$ and $u^{\prime}(1)=-\infty$ In the numerical part of the analysis, we use a specification of $u(\cdot)$ which does not satisfy these properties but we check that the resulting solutions are always interior.

11 The assumption that financiers are paid the whole $L$ (rather than $\min \left\{R_{t+1}, L\right\}$ ) greatly simplifies the notation but is inconsequential since, under any of the two modeling alternatives, the optimal $R_{t+1}$ is always larger than $L$.

12 This interpretation might include thinking about $r_{t}$ as a reduced-form for the risk-adjusted required rate of return that risk-averse but well-diversified financiers demand on the securities issued by the entrepreneurs. Closing the model along these lines would require referring explicitly to the systematic and nonsystematic components of the risk attached to those securities, and any other determinant of investors' required risk premia. Intuitively, $r^{L}$ and $r^{H}$ might correspond to situations in which systematic risk is perceived to be low and high, respectively, perhaps due to the intensity of the correlation between project failures. 
ing. ${ }^{13}$ Alternatively, the assumption may capture the fact that the return entrepreneurs require on the wealth invested in their own projects is larger than the returns financiers require on presumably better diversified and more liquid investment portfolios.

The focus on short-term debt is also standard in the literature (e.g. Kiyotaki and Moore, 1997, and Cooley and Quadrini, 2001) and is adopted mainly for tractability: it makes the state variable that describes the firm's capital structure unidimensional. Allowing for debts with arbitrary maturities, possibly issued at different dates and under different conditions would unbearably multiply the dimensions of the state space. We have explored the model under alternative financial structures which can still be described in a compact manner (e.g. those in which, at the start-up date, short-term debt is combined with arbitrary amounts of consols) and the results are qualitatively and quantitatively very similar. ${ }^{14}$

Finally, to rationalize the inability of the entrepreneur to recapitalize the firm with his outside wealth (implying $c_{t} \geq 0$ ), notice that entrepreneurs are penniless when born and their outside wealth will remain zero if they immediately consume the dividends received from the firm. Imposing $c_{t} \geq 0$ implies that any "precautionary savings" that the entrepreneur might want to have to isolate his firm from fluctuations in $r_{t}$ must be held within the firm, in the form of lower leverage. ${ }^{15}$

13 For a calibration of the tax advantage of debt, see Hennessy and Whited (2005).

14 By considering a limited set of standard financing alternatives, our analysis falls within the classical capital structure tradition. The efficiency lost by not examining more general financing contracts is not so much related to the way the contracts we consider depend on the firm cash flows (whose variation is trivial in our model), but on the fact that the contracts last one period and are not contingent on the realization of the aggregate state variable.

15 If the best return an entrepreneur can get on funds invested outside the firm is $r_{t^{\prime}}$ then this assumption implies no loss of efficiency since there is no reason why an entrepreneur would prefer keeping precautionary savings outside the firm rather than reducing its leverage. If anything, the latter has the advantage of reducing potential conflicts of interest with the financiers (e.g. if limited liability provisions constrain the capacity of the entrepreneur to commit to recapitalize the firm in due course). 



\section{The case without aggregate uncertainty}

This section focuses on firms' dynamic financing decisions in the economy in which financiers' opportunity cost of funds, the risk free rate $r_{t}$, remains constant, i.e. $r^{L}=r^{H}=r$. In the absence of this source of aggregate uncertainty, the solution to the firms' dynamic optimization problem and its implications for firm entry can be analytically characterized. The analytical results will help understand the logic of the numerical results obtained for the economy with random fluctuations in $r_{t}$.

\subsection{Firms' dynamic financing problem}

Without uncertainty about the risk-free rate, the only state variable relevant for the optimal dynamic financing problem of a firm that remains productive at a given date is the repayment obligation $R$ derived from the debt issued in the prior debt. Such a firm will have a cash flow $y$ resulting from its prior period of operation and will have to decide on the debt issued in the current date $\left(b, R^{\prime}\right)$, where, to skip time subscripts, we use the convention of identifying the state variable for the next date as $R^{\prime}$. The dividend resulting from the refinancing decision will be $c=y+b-R \geq 0$. To take into account the moral hazard problem derived from the unobservability of the entrepreneur's choice of $p$, we extend the description of the debt contract to the triple $\left(p, b, R^{\prime}\right)$ and establish the connection between $p$ and the pair $\left(b, R^{\prime}\right)$ through an incentive compatibility condition.

Assuming that the firm that remains productive is always able to find financing for one more period, its optimal dynamic financing problem can be stated in the following recursive terms: ${ }^{16}$

$$
v(R)=\max _{p, b, R^{\prime}}(y+b-R)+\beta\left[u(p)+p v\left(R^{\prime}\right)\right]
$$

subject to

$$
\begin{gathered}
p=\arg \max _{x \in[0,1]} u(x)+x v\left(R^{\prime}\right), \\
p R^{\prime}+(1-p) L=b(1+r), \quad \text { and } \\
y+b-R \geq 0,
\end{gathered}
$$

where $v(\cdot)$ is the entrepreneur's value function. The right-hand side in (1) reflects that the entrepreneur maximizes his dividend in the decision date plus the discount-

We will not formalize the uninteresting case of non-failing firms which, following an explosive debt accumulation path, become unable to refinance their debt after a number of periods. Under resonable parameterizations those paths are incompatible with obtaining funding for the initial investment. 
ed value of the private benefits $u(p)$ received in the next date plus the discounted expected continuation value after one period - continuation value to the entrepreneur is $v\left(R^{\prime}\right)$ if the firm remains productive and zero otherwise. ${ }^{17}$

Equation (2) is the entrepreneur's incentive compatibility condition which entails a trade-off between the utility derived from private benefits $u(p)$ (decreasing in $p$ ) and the expected continuation value $p v\left(R^{\prime}\right)$ (increasing in $p$ ). Since we have assumed that the curvature of $u(p)$ is enough to guarantee interior solutions for $p$, the first order condition

$$
u^{\prime}(p)+v\left(R^{\prime}\right)=0
$$

can be conveniently used to replace (2).

Equation (3) is the participation constraint of the financiers---it says that the effective repayments received after one period $\left(R^{\prime}\right.$ in case of success and $L$ in case of failure) must imply an expected return $r$ on the extended funding $b .^{18}$ The third and last constraint (4) imposes the non-negativity of the entrepreneur's dividend.

In order to reduce the maximization problem in the RHS of (1) -the stage problemto one with a single decision variable and a single constraint, we establish the following intuitive result. All proofs are in the Appendix.

Lemma $1 \quad$ The value function $v(R)$ is strictly decreasing for all leverage levels $R$ for which refinancing is feasible.

With $v\left(R^{\prime}\right)<0$ and $u^{\prime}(p)<0$, (5) implicitly defines a function $p=P\left(R^{\prime}\right)$ with $P^{\prime}\left(R^{\prime}\right)<0$. Using it to substitute for $p$ and solving for $b$ in (3) yields:

$$
b=B\left(R^{\prime}\right) \equiv \frac{1}{1+r}\left[L+P\left(R^{\prime}\right)\left(R^{\prime}-L\right)\right]
$$

This function has a slope

$$
B^{\prime}\left(R^{\prime}\right)=\frac{1}{1+r}\left[P\left(R^{\prime}\right)+P^{\prime}\left(R^{\prime}\right)\left(R^{\prime}-L\right)\right]<\frac{1}{1+r}
$$

which, assuming $P(L)>0$ is definitely positive for $R^{\prime}$ close to $L$, but may become negative for some larger values of $R^{\prime}$. Hence, as in other corporate finance problems, the relationship between debt value $b$ and the promised repayment $R^{\prime}$ may be non-monotonic, although of course only the upward sloping section(s) of $B\left(R^{\prime}\right)$ would be relevant when solving (1). To avoid complications related to discontinuities that may emerge if $B\left(R^{\prime}\right)$ has several local maxima, we adopt the following assumption:

Assumption $1 \quad B\left(R^{\prime}\right)$ is single-peaked, with a maximum at some $\overline{\bar{R}}$.

17 Recall the comment made in Footnote 11.

18 We have written it directly as an equality since, rather than leaving a surplus to the financiers, entrepreneurs would trivially prefer to pay such surplus as a contemporaneous dividend to themselves. 
This assumption is always satisfied under the parameterizations explored in the numerical part of the paper. ${ }^{19}$

Using the function $B\left(R^{\prime}\right)$ (which embeds (2) and (3)), the stage problem in (1) can be compactly expressed as:

$$
\begin{aligned}
& \max _{R^{\prime}} y+B\left(R^{\prime}\right)-R+\beta\left[u\left(P\left(R^{\prime}\right)\right)+P\left(R^{\prime}\right) v\left(R^{\prime}\right)\right] \\
& \text { s.t.: } y+B\left(R^{\prime}\right)-R \geq 0
\end{aligned}
$$

where the only decision variable is $R^{\prime}$ and the only remaining constraint is a rewritten version of (4). Our first proposition establishes the key properties of the solution to this problem.

Proposition 1 The solution to the equation $B^{\prime}\left(R^{*}\right)+\beta P\left(R^{*}\right) v^{\prime}\left(R^{*}\right)=0$ if it exists, defines a unique target leverage level $R^{*} \leq \overline{\bar{R}}$ such that:

1. For $R \leq[0, \bar{R}]$ where $\bar{R} \equiv y+B\left(R^{*}\right)$, the non-failing firm issues new debt $R^{\prime}=R^{*}$, current debtholders get fully paid back, and the entrepreneur's dividend is $y+B\left(R^{*}\right)-R$.

2. For $R \in(\bar{R}, y+B(\overline{\bar{R}})]$, the firm issues new debt $R^{\prime}=\mathrm{B}^{-1}(\mathrm{R}-\mathrm{y}) \in\left(R^{*}, \overline{\bar{R}}\right]$, current debtholders get fully paid back, and the dividend is zero.

3. For $R>y+B(\overline{\bar{R}})$, the firm cannot be refinanced and is liquidated.

\subsection{Implied dynamics}

The analysis of the dynamics of the short-term debt of a non-failing firm can be described with reference to a phase diagram whose elements emanate directly from Proposition 1. Figure 1 describes a situation in which there is a unique stable steady state with some leverage level $R=R^{*}$ that non-failing firms reach in finite time.

The diagram maps a non-failing firm's current repayment obligation $R$ onto its repayment obligation in the following date $R^{\prime}$ The thicker curve represents the mapping of $R$ into $R^{\prime}$ according to the firm's optimal refinancing decisions. By Proposition 1 , such curve is piece-wise defined by the horizontal line $R=R^{*}$ which corresponds to the target leverage ratio and the upward sloping curve implicitly defined by the boundary of the refinancing constraint (9). This boundary can be described as $R^{\prime}=B^{-1}(R-y)$, which is directly connected to (the inverse of) the upward-slopping section of the single-peaked $B\left(R^{\prime}\right)$ schedule. This curve has a slope strictly larger than one (since $B^{\prime}\left(R^{\prime}\right)<1$ ) and is defined for $R \in(y, y+B(\overline{\bar{R}})]$ (since for $R<y$, any $R^{\prime}>0$ satisfies (9)). Satisfying (9) requires choosing $R^{\prime} \leq B^{-1}(R-y)$. Hence, given the relative position of this curve and the horizontal line $R^{\prime}=R^{*}$ it is obvious that reaching the target $R^{*}$ is feasible if and only if current repayment obligations

19 Expressing the assumption in terms of primitives is difficult, since $P(R)$ involves the value function $v(R)$ which can only be found by solving the optimization problem. 
are $R \leq \bar{R} \equiv y+B\left(R^{*}\right)$. Thus the phase diagram describing the dynamics of $R$ is given by the thick inverse-L shaped curve in Figure 1.

Phase diagram with a stable steady state

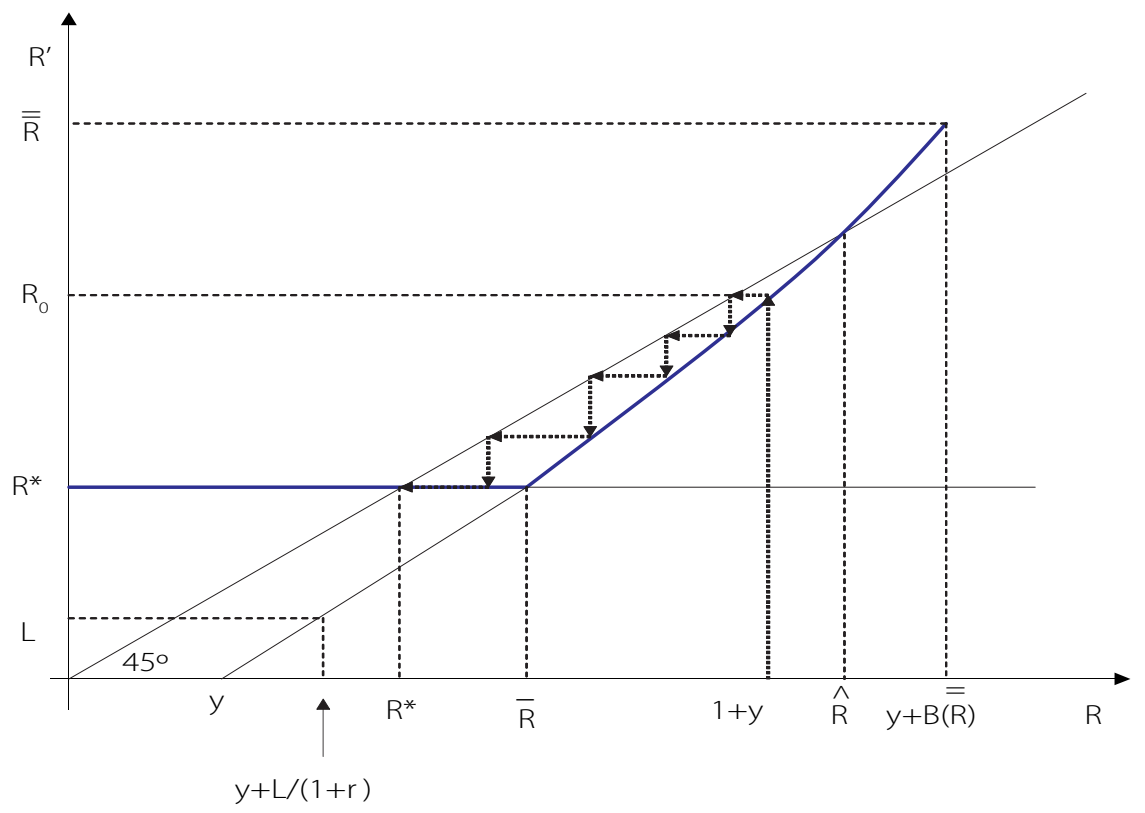

This figure plots the repayment obligation $R^{\prime}$ that results from the optima! refinancing decision of a nonfailing firm whose current repayment obligation is $R$. The arrows indicate the dynamics of the firm's repayment obligation along a non-failing path that converges in five periods to the target leverage level.

In Figure 1 the phase diagram crosses the 45-degree line twice, once on the horizontal section, at $R=R^{*}$, and another time on the vertical section, at a point denoted $R=\hat{R}$. This is just one of the three possible situations that one may have. Alternatively, the piece-wise curve may fully lay to the left of the 45-degree line, but in this case, refinancing dynamics is explosive. As yet another alternative, the curve may intersect the 45 -degree line only once, on its horizontal section, which will be the case if $y+B(\overline{\bar{R}})<\overline{\bar{R}}$. In this case refinancing dynamics is qualitatively the same as in the first case.

Dynamics around the intersection with the 45-degree line that occurs at the horizontal section of the phase diagram is stable, while around the intersection at the upward slopping section it is instable. So the horizontal intersection (if it exists) identifies the only stable steady state in the refinancing problem. The feasibility of a non-explosive financing path for the firm requires that the upper intersection occurs at some $\hat{R} \geq 1+y$, since financing the initial investment is equivalent to having to refinance an initial obligation of 1 without the cash $y$ resulting from a prior period of successful operation. ${ }^{20}$

The following proposition summarizes the implications of this discussion.

20 When the relevant curve only intersects the 45 -degree line at $R^{*}$, having a non-explosive financing path for the firm requires $B(\overline{\bar{R}}) \geq 1$. 
Proposition 2 The firm's optimal financing path is non-explosive if and only if $\min \{\hat{R}, \overline{\bar{R}}\} \geq \max \{1+y, \bar{R}\}$, where $\hat{R}$ is defined by $y+B(\hat{R})-\hat{R}=0$. The non-explosive optimal financing path is unique and converges in finite time to the steady state associated with the target leverage level $R^{*}$.

The prior discussion identifies two types of situations depending of the relative position of $1+y$ and $\bar{R}$. If $\bar{R}>1+y$ (and $\min \{\hat{R}, \overline{\bar{R}}\} \geq \bar{R})$, the firm reaches its target leverage level $R^{*}$ from the start (possibly paying an initial dividend to the entrepreneur out of the proceeds from debt issuance) and, insofar as it does not fail, remains there forever, rolling over its debt and paying a dividend $y-R^{*}$ to the entrepreneur at the end of every period. Otherwise, as illustrated in Figure 1 , it starts assuming some repayment obligation $R_{0}>R^{*}$ such that $B\left(R_{0}\right)=1$ and pays no initial dividend. Afterwards, insofar as it does not fail, gradually reduces its leverage up to reaching the target leverage $R^{*}$ after a finite number of periods. At that point, it starts rolling over its debt and paying dividends $y-R^{*}$.

\subsection{Comparative statics and dynamics}

In the next proposition, we establish the properties of the stable steady-state.

Proposition 3 The steady-state target leverage level $R^{*}$ is strictly larger than $L$ increasing in $y$ and $L$, and decreasing in $r$, while its dependence with respect to $\beta$ is ambiguous. The implied probability of default, $1-p^{*}$, is strictly positive, increasing in $L$ and decreasing in $y$ and $\beta$, while its dependence with respect to $r$ is ambiguous.

The main rationale for firms to remain levered in the long run is the difference between $\beta$ and $1 /(1+r)$. However, optimal leverage is limited by the moral hazard problem which makes $p$, ceteris paribus, decreasing in $R$. The resolution of the trade-off between the fundamental value of leverage and its incentive-related costs drives most of the results, including the effects of varying $\beta$ and $r$ (and the ambiguity of some of the signs).

When financiers' opportunity cost of funds $r$ increases, target leverage decreases, since the fundamental value of leverage decreases at the same time as the incentiverelated cost of leverage increases due to the reduction in the firm's continuation value. This last effect explains why, in spite of reducing leverage, a higher $r$ does not necessarily lead to a lower probability of default $1-p^{*}{ }^{21}$ When the entrepreneurs' discount factor $\beta$ increases the same logic leads to mirrow-image implications: the fundamental value of leverage decreases but the value of continuation increases and, hence, incentives improve, creating a force that pushes for higher leverage. So in this case, the probability of default falls, but target leverage may increase or decrease.

Increasing the success cash flow $y$ increases the entrepreneur's incentives to avoid default (so as to preserve the larger continuation value) and, hence, the capacity of

21 Yet, in all our numerical simulations, the effect due to the reduction in leverage dominates, making the default risk associated with target leverage decreasing in $r$. 
the firm to increase its target leverage $R^{*}$ while actually reducing the default probability $1-p^{*}$. The effects of the liquidation value $L$ on target leverage and the associated default are more intriguing. Making $L$ larger increases the firm's continuation value, but makes it so through the specific channel of reducing the cost of future failure. This alters the trade-offs relevant for the choice of optimal leverage, which increases up to a point in which the associated default probability is unambiguously higher. $^{22}$

We now turn to analyzing the effects of the parameters on the upward slopping section of the phase diagram. This will tell us about the repayment obligation $R^{\prime}$ and the associated default probability $1-p\left(R^{\prime}\right)$ of those firms whose current leverage is still too high to reach the target leverage level $R^{*}$.

Proposition 4 For $R>\bar{R}$, the firm's optimal refinancing, if feasible, leads to an above-target leverage level $R^{\prime}$ which is increasing in $R$ and $r$ and decreasing in $\beta, y$, and $L$. The implied probability of default, $1-p\left(R^{\prime}\right)$, is strictly positive, and responds in the same direction as $R^{\prime}$ to changes in parameters.

Importantly, when target leverage cannot yet be reached, increasing financiers' opportunity cost of funds $r$ aggravates the firm's excessive leverage and excessive default risk problems (while increasing $\beta$, $y$, or $L$ makes these problems less severe). So there is a sharp contrast between the effects of some parameters (and specifically $r$ ) on target leverage and on the effective leverage of the firms that are above their target.

Combining the results from Propositions 3 and 4, Figure 2 summarizes the implications of a shift in $r$ for the dynamics of firms' financing. The dashed phase diagram corresponds to a higher $r$ than the solid phase diagram. With a larger $r$, target leverage is lower, but the leverage needed to refinance prior debt (or the initial investment) is larger for all $R>\bar{R}$, making the two phase diagrams cross at a single point. Thus an unanticipated, once-and-for-all increase in $r$ may temporarily increase the leverage of some firms, while reducing the leverage of other firms (and the target leverage of all firms).

The intuition is clear: mature firms already at their prior target leverage (the $R^{*}$ associated with the solid curve) can immediately start a process of leverage reduction leading to the new target (the $R^{*}$ associated with the dashed curve), and even achieve the new target in a single period, while younger firms, caught with larger leverage, will face a temporary increase in leverage and will slow down their convergence to target leverage, experiencing higher default rates in part of the transition to the new target.

The effects of decreasing $r$ are also heterogeneous across firms and asymmetric from those of increasing $r$. Following a reduction in $r$, mature firms (as well as younger

22 If empirically, large $L$ corresponds to economies in which the collateral value of the firms' real assets (including real state) is high, this result provides a rationale for view that higher real asset values (e.g. due to a long real state boom) tend to induce larger "risk taking." 
firms whose leverage was above the previous target but below the new one) can reach the new steady state immediately since increasing leverage does not require time. Instead, younger firms with leverage still higher than the new target will merely accelerate their convergence to the new target, experiencing lower default rates in the transition. This suggests that the transitional dynamics of a reduction in $r$ will tend to be quicker than the transitional dynamics caused by a rise in $r$.

\section{Effects of unexpected once-and-for-all changes in $r$}

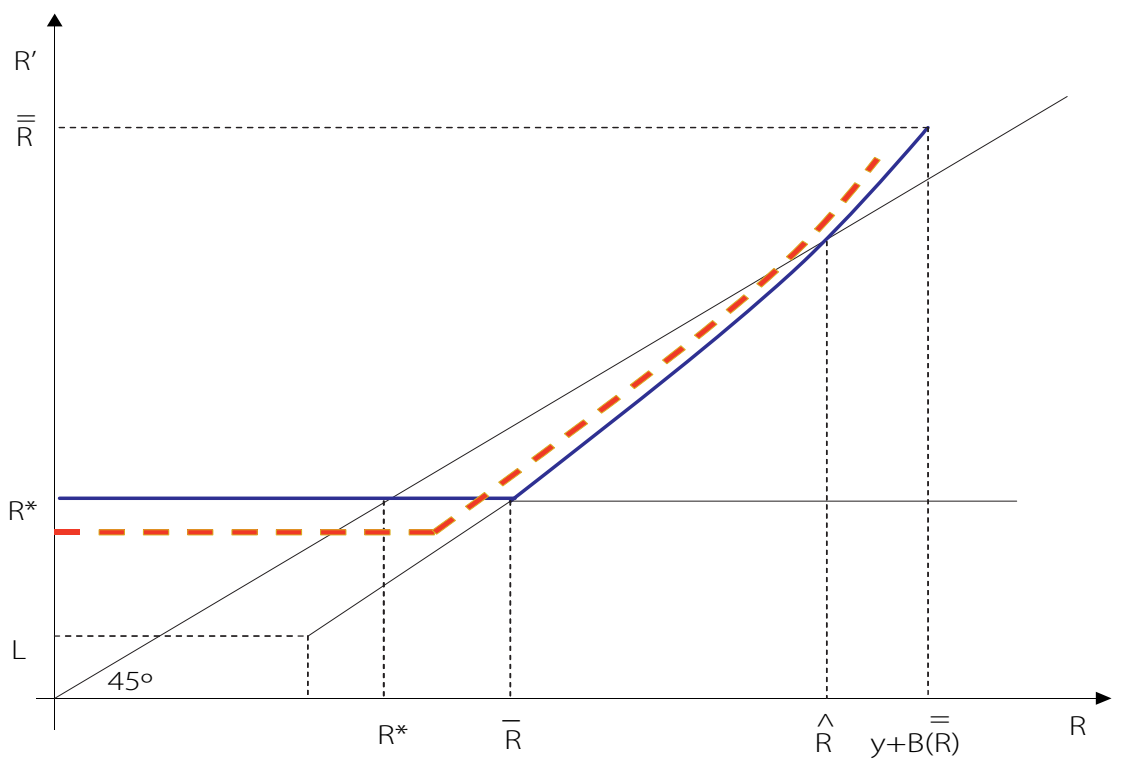

This figure plots the repayment obligation $R^{\prime}$ that results from the optima! refinancing decision of a nonfailing firm whose current repayment obligation is $R^{\prime}$. The red line corresponds to a situation in which financiers' required rate of return is larger than in the situation corresponding to the blue line.

Importantly, the heterogeneity in the cross-sectional response to a shift in $r$, as well as the asymmetry across rises or declines in financiers' opportunity cost of funds, will also arise in the economy with explicit (rationally anticipated) aggregate uncertainty about $r$. The implications of these results for current macroprudential discussions will be discussed in Section 5 .

\subsection{Equilibrium entry}

Assume that, as in Figure 1, we have $\bar{R}<1+y \leq \hat{R}$, so that entering firms start up with a leverage level $R_{0}>R^{*}$ Since the leverage required to start-up a firm is equivalent to having to refinance a repayment obligation $1-y$ the value of a just-entered firm can be expressed as $v(1+y)$. Thus, the equilibrium non-pecuniary cost of entry of the marginal entrant $\theta^{*}$ (which in the absence of aggregate uncertainty is time-invariant) can be obtained from the break-even condition $v(1+y)=\theta^{*}$ As stated in Lemma 1 , the value function is strictly decreasing in the state variable, and, as explained in the proof of Proposition 4, it is also increasing in the parameters $\beta, y$, and $L$, and decreasing in $r$. Moreover, it is easy to check that $\partial v / \partial R+\partial v / \partial y>0$ so that the value of a just-entered firm is indeed strictly increasing in $y$. Thus, the marginal entry cost $\theta^{*}$ is also increasing in $\beta, y$, and $L$, and decreasing in $r$. 
Using the distribution function of $\theta$, the size of the entry flow can be written as

$$
e_{t}=F\left(v(1+y), n_{t}\right),
$$

where $n_{t}$ is the total measure of active firms at date $t$. This establishes a negative relationship between $e_{t}$ and $n_{t}$. But in fact the dynamics of $n_{t}$ is fed by the entry flow $e_{t}$ and solving for equilibrium involves a fixed point argument that is easier to explain (and write mathematically) after referring to the law of movement of the whole distribution of leverage across active firms.

Let $\Psi_{t}(\mathcal{R})$ denote the measure of firms that operate at date $t$ with a promised repayment for next period in the (measurable) set $\mathcal{R}$ and let $R^{\prime}(R)$ denote the phase diagram described in the prior subsections. Then the law of motion of $\Psi_{t}(\mathcal{R})$ can be described as follows:

$$
\Psi_{t}(\mathcal{R})=\int_{0}^{\infty} \mathbb{I}\left(R^{\prime}(R) \in \mathcal{R}\right) P(R) d \Psi_{t-1}(R)+\mathbb{I}\left(R_{0} \in \mathcal{R}\right) F\left(v(1+y), n_{t}\right),
$$

where $\operatorname{II}(C)$ is an indicator function that equals one if the condition $C$ is true and zero otherwise. The first term in the right hand side of (11) contains the contribution to the measure of firms with leverage contained in the set $\mathcal{R}$ at time $t$ of the firms already operative at $t-1$ that survive up to $t$. Those are the firms with different leverage levels $R$ at $t-1$ that (i) survive up to $t$ (which explains the factor $P(R)$ ) and (ii) choose leverage levels $R^{\prime}(R)$ at $t$ within the set $\mathcal{R}$ (which explains the factor $\left.\mathbb{I}\left(R^{\prime}(R) \in \mathcal{R}\right)\right)$. The second term contains the contribution of the flow of entrants, which produces a mass point (of size $e_{t}$ as determined in (10)) at the entry leverage level $R_{0}=R^{\prime}(1+y)$ (recall the discussion around Figure 1).

With this notation, the total number of operating firms at any date $t$ must be equal to the result of integrating the measure of firms across all possible debt levels, i.e. must satisfy $n_{t}=\Psi_{t}\left(\mathbb{R}^{+}\right)$. However, $n_{t}$ also appears in the last term of (11), affecting it negatively and thus making $\Psi_{t}\left(\mathbb{R}^{+}\right)$a decreasing function of $n_{t}$ say $N_{t}\left(n_{t}\right)$. Hence, the equilibrium number of firms at date $t$ can be characterized as the unique fixed point of the function $N_{t}\left(n_{t}\right)$. In the absence of aggregate uncertainty, as it is the case in this section, and under paramerizations that make entry viable, the economy will converge to a steady state in which the distribution $\Psi_{t}(\mathcal{R})$, the entry flow $e_{t}$ and the equilibrium number of firms $n_{t}$ are all time-invariant. 


\section{The case with aggregate uncertainty}

We now turn to the case in which financiers' opportunity cost of $r_{t}$ follows a Markov chain with two possible values, $r^{L}$ and $r^{H}$ with $r^{L}<r^{H}$. We first extend the equations needed to characterize equilibrium in this case and then develop the rest of the analysis numerically, for a realistic parameterization of the model. The numerical approach is justified by the fact that aggregate uncertainty will tend to increase the number of ambiguous-to-sign effects. ${ }^{23}$ Additionally, the quantitative exercise will inform about the order of magnitude of the effects identified in the analytical part -including aggregate effects which can only be found taking the whole aggregate dynamics of leverage into account.

\subsection{Equilibrium conditions}

Extending the optimal dynamic financing problem stated in (1)-(4) requires writing the value function as $v(R, r)$ rather than $v(R)$ to reflect that financiers' opportunity cost of funds $r$ at a given date is a relevant descriptor of the aggregate state of the economy. By the same token, the continuation value of the non-failing firm, previously written as $v\left(R^{\prime}\right)$, must now be written as $E\left[v\left(R^{\prime}, r^{\prime}\right) \mid r\right]$ where $r^{\prime}$ denotes financiers' opportunity cost of funds one period ahead and the expectation is taken with the information available at the decision date, for which $r$ is a sufficient statistic. ${ }^{24}$

For the analysis of the problem, objects such as $P\left(P^{\prime}\right)$ implicitly defined by $(5)$ and $B\left(R^{\prime}\right)$, defined in (6), have to be replaced by $P\left(R^{\prime}, r\right)$ and $B\left(R^{\prime}, r\right)$ to reflect their dependence, through $E\left[v\left(R^{\prime}, r^{\prime}\right) \mid \mathrm{r}\right]$, on the value of the state variable at the decision date. Other adaptations of the problem and the nature of its solution are relatively straightforward. In essence, firms will have a different target leverage $R^{*}(r)$ for each value of $r$, and the dynamics of leverage when the target cannot be reached will also differ across the two states of $r$. The counterpart to the phase diagram depicted in Figure 1 is now a couple of two curves of the form $R^{\prime}(R, r)$ for $r=r^{L}, r^{H}$. In Figure 3, generated under the parameterization explained below, target leverage and leverage dynamics under $r=r^{L}\left(r=r^{H}\right)$ is described by the blue (red) phase diagram. ${ }^{25}$ The

23 Some important effects were already analytically ambiguous when moving $r$ in an unexpected, onceand-for-all fashion in the prior section.

$24 r_{t}$ is not the only aggregate state variable in the model but is the only one relevant for the decision problem of non-failing firms. The measure of firms in operation $n_{t}$ is also an aggregate state variable and it is relevant for the entry decisions of novel entrepreneurs. However, $n_{t}$ only affects the distribution of the non-pecuniary entry costs. The fact that the value of firms to entrepreneurs after entry is independent of $n_{t}$ (or any other statistic associated with the cross-section of operating firms) greatly simplifies the model.

25 Notice that the relative position of these state-contingent phase diagrams is qualitatively identical to that of the phase diagrams in Figure 2, which corresponded to two economies with different time-invariant values of $r$. 
underlying parameterization implies sizable differences in target leverage across states (the intercept of each curve) and, for a start-up firm, a much larger transition to target leverage under high interest rates.

\section{Leverage dynamics with aggregate uncertainty}

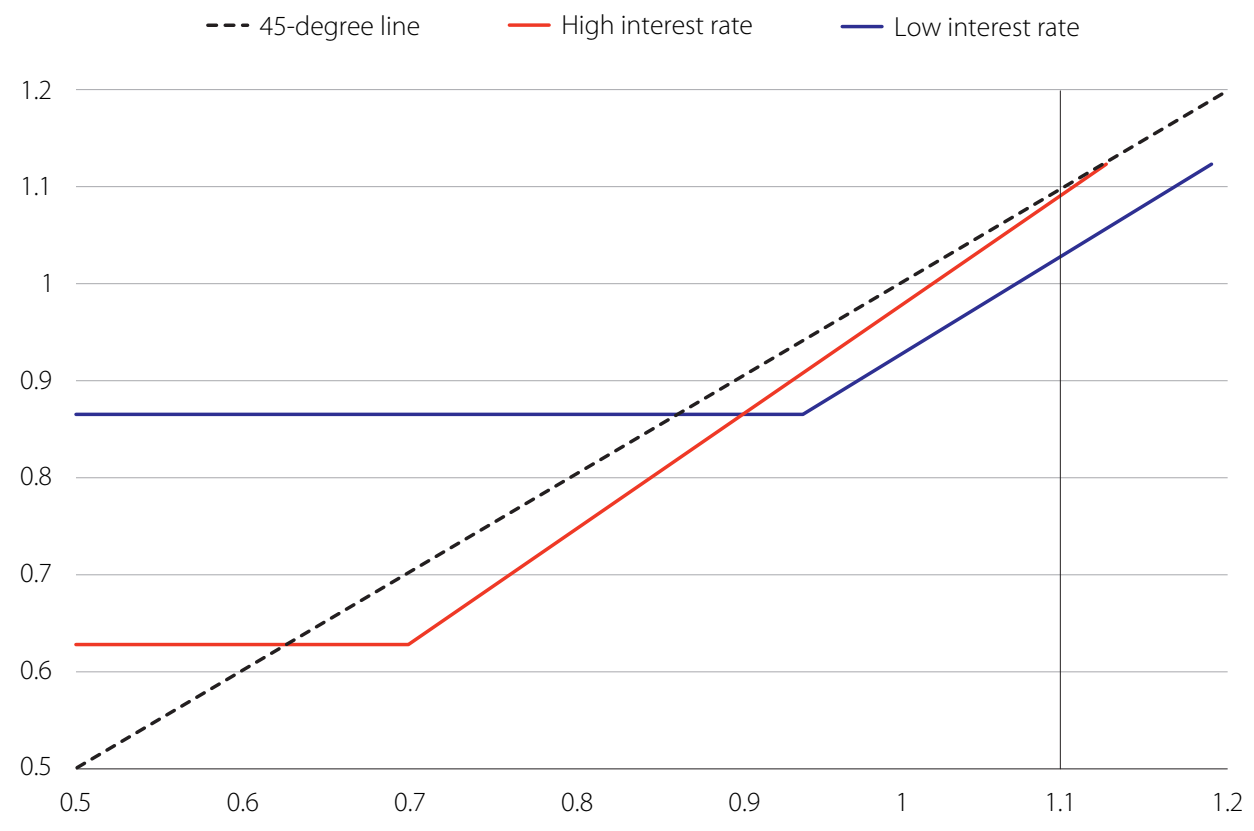

This figure is the counterpart of Figure 1 for the economy with aggregate uncertainty. The results correspond to the economy whose parameters are described in Table 1. Each curve represents the phase diagram that summarizes the optimal refinancing decisión (future leverage) of non-failing firms (vertical axis) conditional on their current leverage (horizontal axis) and the prevailing interest rate. The optimal policy for periods of low (high) interest rates appears in blue (red) color. Differences in target leverage across states are quite sizable. The vertical black line helps identifying (on the corresponding curve) the leverage with which entering firms start up in each state.

As for the free-entry condition (10) and the law of motion for the distribution of firms' leverage (11), the adaptations are also simple. The dynamics of $\Psi_{t}(\mathcal{R})$ will in this case be driven not just by the endogenous forces of exit (due to default) and entry, but also by the exogenous Markov-chain dynamics of $r_{t}$. In this context, the economy does not converge to a time-invariant distribution of leverage levels, but we can still characterize a stationary equilibrium in which the distribution of leverage across firms follows an invariant law of motion. Intuitively, the economy will oscillate around the two steady states that would be reached if it remained in each of the two possible interest-rate states, $r^{L}$ or $r^{H}$, forever. The formal definition of this equilibrium is the following:

Definition 1 A stationary equilibrium in this economy is an invariant law of motion for the distribution of firms' leverage $\Psi_{t}(\mathcal{R})$ and a policy function $R^{\prime}(R, r)$, mapping firms' current debt $R$ and the aggregate state variable $r$ into their next-period leverage $R^{\prime}$, such that:

- Incumbent entrepreneurs solve their dynamic refinancing problem optimally. 
- Novel entrepreneurs decide optimally on entry.

- The law of motion for $\Psi_{t}(\mathcal{R})$ satisfies

$$
\Psi_{t}(\mathcal{R})=\int_{0}^{\infty} \mathbb{I}\left(R^{\prime}\left(R, r_{t}\right) \in \mathcal{R}\right) P(R) d \Psi_{t-1}(R)+\mathbb{I}\left(R^{\prime}\left(1+y, r_{t}\right) \in \mathcal{R}\right) F\left(v\left(1+y, r_{t}\right), n_{t}\right)
$$

where $n_{t}$ is the measure of active firms, which solves $n_{t}=\Psi_{t}\left(\mathbb{R}^{+}\right)$.

The structure of the model allows us to solve for equilibrium in a conveniently recursive manner. Obtaining $R^{\prime}(R, r)$ involves solving the dynamic programming problem of surviving firms, which is independent of $n_{t}$ and the very distribution of leverage across firms. We address this using value function iteration methods. The dynamics of the aggregate distribution of leverage can be tracked using (12), which combines the continuation probabilities and the refinancing decisions of surviving firms with the free-entry condition and the fixed-point condition that, as explained in subsection 3.4, determine the entry of new firms and the equilibrium measure of firms in each date.

\subsection{Parameterization}

To proceed with the numerical analysis of the model, we need to specify the private benefits function $u\left(p_{t}\right)$ and the density of the distribution of the entry $\operatorname{costs} f\left(\theta, n_{t}\right)$. We adopt the following functional forms:

$$
u\left(p_{t}\right)=\mu\left(1-p_{t}^{\alpha}\right), \text { with } \mu>0 \text { and } \alpha>1,
$$

and

$$
f\left(\theta, n_{t}\right)=\frac{1}{n_{t}} \exp \left(-\frac{1}{n_{t}} \theta\right)
$$

The function described in (13) does not satisfy $u^{\prime}(0)=0$ and $u^{\prime}(1)=-\infty$ but we check that the equilibrium values of $p_{t}$ are always interior under our choice of parameters. (14) implies that entry costs are exponentially distributed and, as required, increase in the sense of first-order stochastic dominance when the measure of operating firms $n_{t}$ increases.

Under (13) and (14), the model has nine parameters: four related to interest rate dynamics $\left(r^{H}, r^{L}, \pi_{H H^{\prime}}\right.$ and $\left.\pi_{L L}\right)$, the entrepreneurs' discount factor $\beta$, the per period cash flow $y$ of operating firms, the liquidation value $L$ of failing firms, and the two parameters of the private benefit function $(\alpha$ and $\mu)$. We consider that a model period corresponds to a year, which would be consistent with firms issuing one-year debt and revising their financing policies on an annual basis. Table 1 describes the values of the parameters used to obtain our numerical results.

As for interest rate dynamics, we estimate a symmetric Markov chain with data on US real interest rates, 1984-2009, taken from Thomson Datastream. This yields $r^{L}=$ $0.23 \%, r^{H}=3.42 \%$ and $\pi_{L L}=\pi_{H H}=0.9293$, capturing rather large and long-lasting 
fluctuations in the opportunity cost of funds (state shifts occur on average every 14 years). ${ }^{26}$

The discount factor $\beta$ embeds a measure of entrepreneurs' required expected rate of return on their own wealth, $1 / \beta-1$. Following other papers on entrepreneurial financing, we set $\beta=0.9386$ so as to match the average real rate of return historically observed in the US stock market, which is of about $6.5 \%$.

\section{Parameter values}

\begin{tabular}{lrr} 
Description & Parameter & Value \\
\hline High-state interest rate & $r^{H}$ & $3.42 \%$ \\
\hline Low-state interest rate & $r^{L}$ & $0.23 \%$ \\
\hline State persistence parameter & $\pi_{L L}=\pi_{H H}$ & 0.9293 \\
\hline Entrepreneurs' discount factor & $\beta$ & 0.9386 \\
\hline Net cash flow & $y$ & 0.10 \\
\hline Liquidation value of assets & $L$ & 0.2998 \\
\hline Scale parameter - private benefit function & $\mu$ & 0.1739 \\
\hline Elasticity parameter - private benefit function & $\alpha$ & 8.6529 \\
\hline
\end{tabular}

This table describes the parameters used to generate our numerical results. The first block of parameters refers to interest rate dynamics. The second block refers to entrepreneurs' prefer-ences and investment technologies. Empirical sources and other criteria for the setting of these parameters within a realistic range are described in the main text.

We set the per period cash flow $y$ equal to $10 \%$ of the initial investment -recall that such investment is normalized to one and does not include the non-pecuniary costs incurred by entrepreneurs upon entry. Given the other parameters of the model, this value of $y$ implies interest coverage ratios (i.e. due interest payments $R-b$ over cash flow $y$ ) of $11.4 \%$ and $18.6 \%$ for firms that reach target leverage with low and high interest rates, respectively. These numbers are consistent with average values reported in the literature (e.g. Blume et al. (1998) that report an average interest coverage ratio of $15.8 \%$ ). They also imply, for the firms at target leverage, a return on assets (computed as the yearly cash flow $y$ divided by the sum of debt value $b$ plus equity value $v$ ) of $4.1 \%$ and $5.0 \%$ under low and high interest rates, respectively. ${ }^{27}$

The liquidation value $L$ and the parameters of the private benefit function, $\alpha$ and $\mu$, are calibrated so as to match three empirical moments. Since conventional sources of data do not include firms in the earliest stages of their lives, we match these empirical moments with the moments that the model generates for mature firms (defined as firms that have reached their target leverage at some point in history). The first moment we match is an aggregate average default rate (computed in the model

26 Thus, the current calibration captures swings between the high-rates of the Volcker era, the rather lowrates of the Greenspan era, etc. Nothing would prevent extending the analysis to the case in which interest rates follow a Markov process with $n>2$ states. But the current exercise facilitates the reporting of the results and the fixing of intuitions. The constraint $\pi_{L L}=\pi_{H H}$ is adopted to guarantee that any asymmetry obtained in the results is not due to the asymmetry of the Markov chain.

27 Of course, the variation in this ratio is entirely due to total firm value, which is lower under high rates. 
as $1-p$ ) of $1.46 \%$, which is the value reported in Standard \& Poor's (2007) for the period 1983-2007. The second is an average leverage ratio (computed in the data as book value of debt over book value of debt plus market value of equity, and in the model as $b /(b+v))$ of $35 \%$, which is in line with average values observed in Compustat. ${ }^{28}$ Finally, we match an average recovery rate (i. e. ratio of $L$ to outstanding debt obligations $b$ ) of $41.24 \%$, which is the average observed in Edward Altman's Master Default Database over the same period. ${ }^{29}$

Simulated moments (in \%)

TABLE 2

\begin{tabular}{cccc} 
& $\begin{array}{r}\text { Unconditional } \\
\text { mean }\end{array}$ & $\begin{array}{c}\text { Mean } \\
\text { under } r^{L}\end{array}$ & $\begin{array}{r}\text { Mean } \\
\text { under } r^{H}\end{array}$ \\
\hline Average default rate & 1.71 & 2.03 & 1.38 \\
\hline Firms at target & 1.46 & 1.97 & 0.78 \\
\hline Firms above target, below median & 2.74 & 2.55 & 2.94 \\
\hline Firms above target, above median & 4.45 & 3.80 & 5.13 \\
\hline Average leverage ratio & 36.21 & 39.45 & 32.78 \\
\hline Firms at target & 35.10 & 39.09 & 29.73 \\
\hline Firms above target, below median & 42.24 & 43.51 & 40.89 \\
\hline Firms above target, above median & 48.80 & 48.57 & 49.03 \\
\hline Average recovery rate & 37.59 & 34.67 & 40.70 \\
\hline Firms at target & 41.12 & 35.13 & 48.57 \\
\hline Firms above target, below median & 34.08 & 32.65 & 35.59 \\
\hline Firms above target, above median & 29.72 & 29.17 & 30.31 \\
\hline Initial valué (=marginal entry cost) & 0.9607 & 1.0547 & 0.8667 \\
\hline Measure of active firms & 7.2216 & 7.1830 & 7.2603 \\
\hline
\end{tabular}

This table reports relevant moments for our economy. Given the parameterization in Table 1, we simulate 1,000 economies for 300 periods and pick only the 25 last periods. Reported moments are calculated by averaging the corresponding moment unconditionally or in each state of the economy. A large proportion of firms are at target leverage a large proportion of time, so the moments for the overall population of firms (first row in each block) and firms at target leverage (second row) are very similar. The third and fourth rows report the averages within the groups of firms that result from dividing firms whose leverage exceeds target leverage in two quantiles. Start-up firms make the vast majority of the top quantile. The last two rows in the table report (moments referred to) the valué of start-ups to their entrepreneurs and the measure of active firms.

Table 2 contains a summary of some of the moments generated by the model under the parameterization that we have just described. It reports both unconditional mo-

28 For instance, Morellec et al. (2008) report an average leverage ratio for Compustat firms of $32 \%$ over the period 1992-2004.

29 Direct measures of the importance of private benefits (and their dependence on entrepreneurial decisions) are hard to obtain since their unobservability is precisely at the root of the moral hazard problem between entrepreneurs and their financiers. Our calibration strategy is based on the observable outcomes of the underlying problem. The parameters on Table 1 imply that the equilibrium flow of private benefits represent on average about $22 \%$ of the cash flow stream $y$ under low interest rates (i.e. about $2.2 \%$ of the initial investment) and about $10 \%$ under high rates (i.e. about $1 \%$ of the initial investment) these numbers are within the range found by Dyck and Zingales (2004) using a very different indirect inference strategy. If shifts in interest rates are caused by monetary policy, these numbers suggest the existence of a pretty sizable "private benefit taking" channel of monetary policy. 
ments (that do not condition on the prevailing interest rate, first column) and moments conditional on low interest rates (second column) and high interest rates (third column). Additionally to the averages over the whole population of active firms, the table shows the averages for firms at target leverage (which are the vast majority most of the periods) and for each of the two quantiles in which we break down the subset of firms with leverage above their target. Since the unconditional mature-firms average of the three variables reported in the three first blocks of the table were calibration targets in our parameterization, the values of the unconditional averages for firms at target leverage are not surprising. The genuinely novel information contained in the table refers to the variation across firms and across interest-rate states that the model is able to generate---which will be key to understand the heterogeneity and asymmetries in the response of firms to shifts in interest rates.

The previous to last row in Table 2 contains the value of start-up firms to their entrepreneurs, $v(1+y, r)$, under each of the possible values of $r$, as well as the unconditional mean. Start-ups are worth almost $22 \%$ more under low interest rates than under high interest rates due to the lower anticipated cost of their leverage (and their larger debt capacity). The last row in Table 2 shows the average measure of active firms which turns out to be about $1 \%$ higher under high interest rates than under low interest rates. The reason whereby low interest rates sustain a lower average measure of active firms is related to the higher leverage and larger failure rate that they produce. Given the high exit rate and our specification of the distribution of entry costs, sustaining an entry level consistent with producing the same measure of active firms as under high interest rates would require a difference in start-up values across states larger than the $22 \%$ that emerges under the current calibration..$^{30}$

Figure 4 describes the paths of total debt $b$ (top panel, in absolute value) and the default rate $1-p$ (bottom panel, in percentage points) for firms started up in periods with low (blue curve) and high (red curve) interest rates. The solid curves are average trajectories. The dashed curves in each color delimit the range of two standard deviations (of simulated trajectories) around the corresponding mean. The figure emphasizes the existence of a financial life cycle whereby firms start up with leverage above their target leverage, which is approached gradually via earnings retention. Convergence to target leverage takes time and over time interest rates change, producing transitional effects and changes in the target. It turns out that after sufficiently many periods (8-9 years in our results), the average trajectories of the firms that started in each states become very similar, i.e. independent of firms' initial state. The two standard deviations bands give an idea of the extent to which firms' individual leverage and default experiences may depend on the evolution of interest rates during their lifetime.

Figure 5 shows the variation in average default rates (in percentage points) after an increase (left panel) and a decrease (right panel) in the interest rate. The variation is computed as the deviation from a counterfactual path in which the interest rate

30 Recall that start-up value equals, in equilibrium, the entry cost of the marginal entering entrepreneur. Unconditionally, the average firm entry and firm exit flows are equal since the measure of active firms fluctuates but is stationary. Average entry and exit rates in each state need not be exactly equal but are very similar. Average exit rates coincide with the average default rates reported in the first row of Table 2. 
does not shift at year $\mathrm{o}$. The various curves represent the average effects for firms that are hit when they are at their target leverage (black line) and when they are above such target. The latter group is divided in two quantiles, one closer (red line) and the other further away (blue line) from target leverage. The well-above target group includes the start-ups.
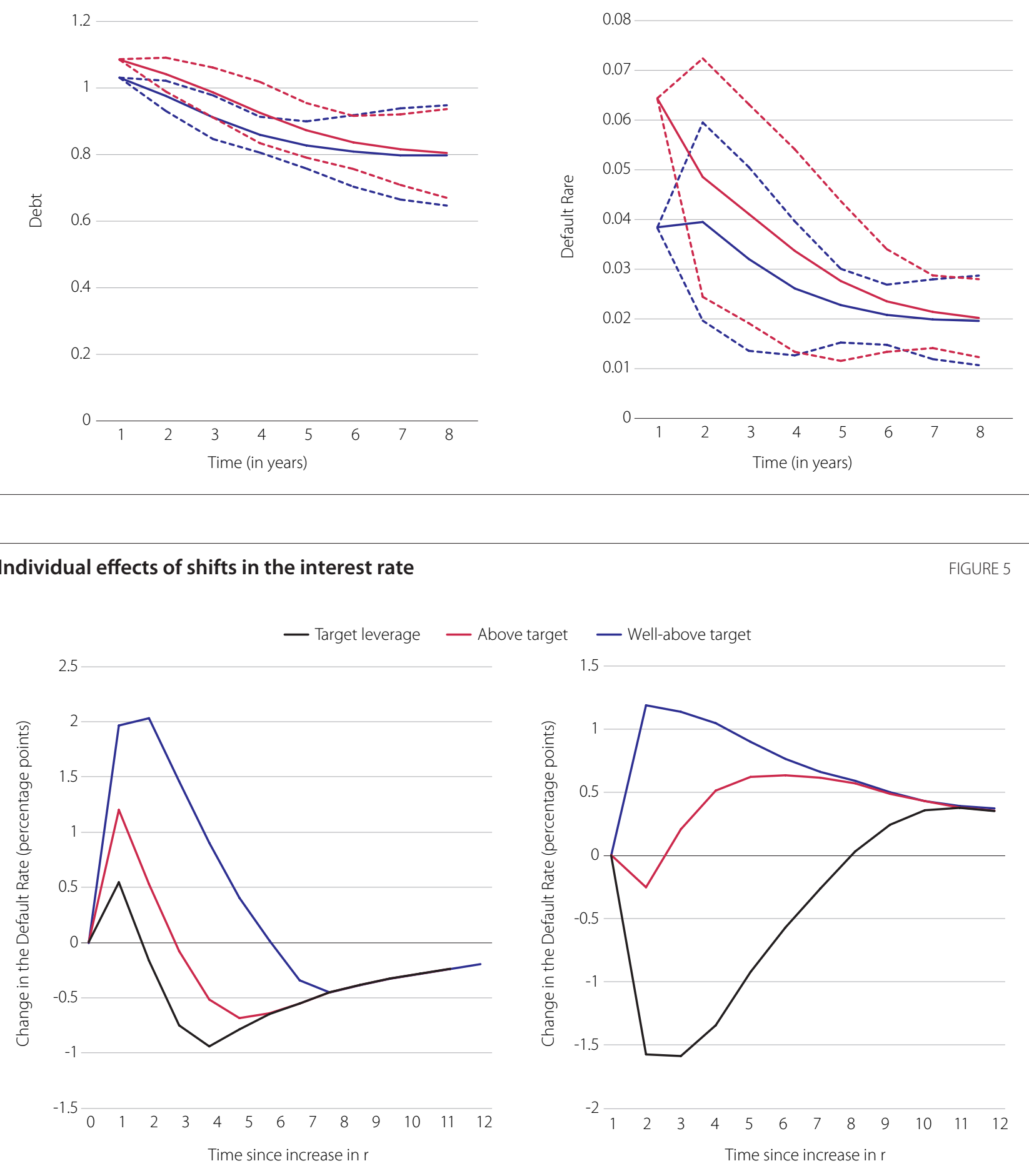
The figure evidences the importance of two key properties of the effects of interest rate shifts in the model: (i) the heterogeneity in the response across firms and (ii) the asymmetry in the effects of interest rate rises vs. interest rate cuts. Both are due to the underlying corporate finance frictions. Following an interest rate rise, firms with higher leverage suffer more from excessive indebtedness (and high default) in the short-run and take it longer to adjust to their new, lower leverage target (which eventually implies a lower default rate). Following an interest rate cut, mature firms adjust to their new, higher target leverage immediately (which explains the shortterm spike in the default rate), while for the youngest firms the cut implies lowering the burden of their excessive leverage and a quicker convergence to the now higher (but still lower than what they have) leverage target.

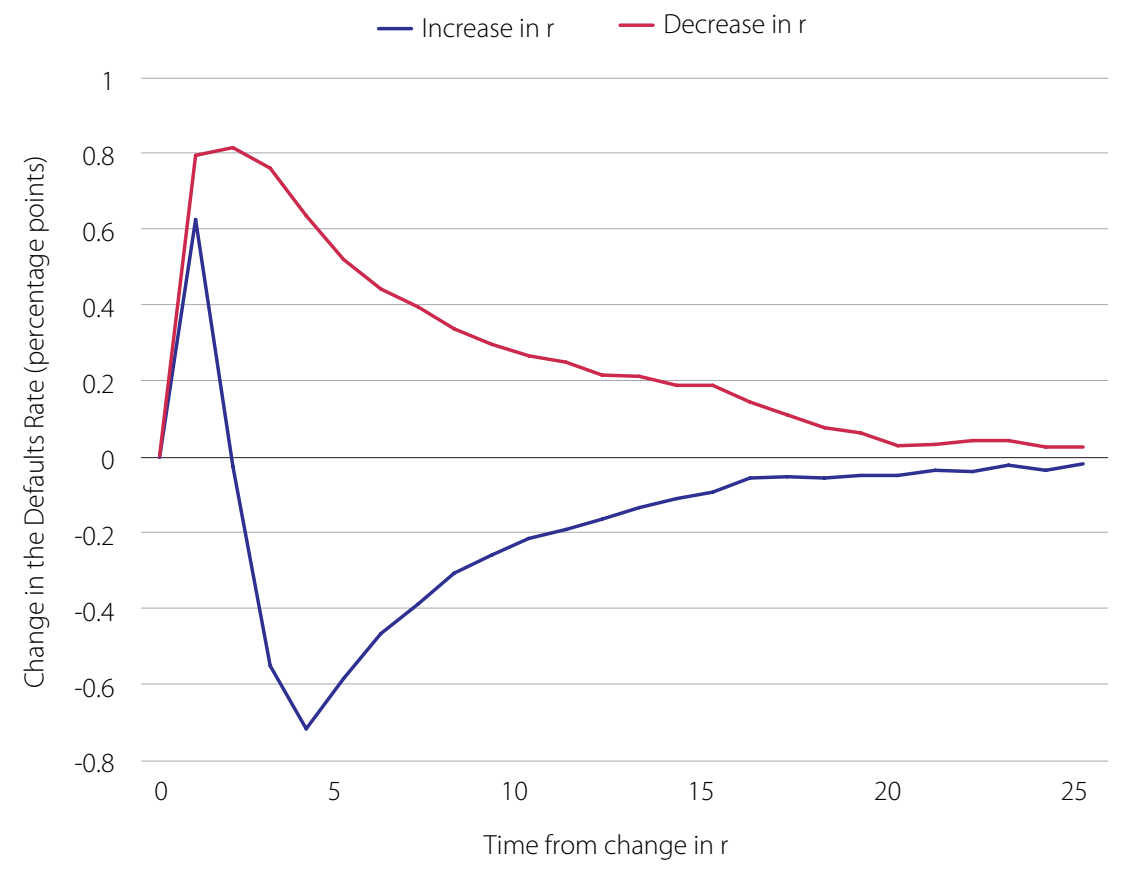

Figure 6 shows the implications of aggregating across the whole population of active firms the effects that we have just commented: it depicts the variation in the aggregate default rate (in percentage points) after an increase (blue line) and a decrease (red line) in the interest rate. As before, the variation is computed as the deviation from a counterfactual path in which the interest rate does not shift at year o. Somewhat surprisingly, in the shortest run any shift in the risk-free rate has a negative impact on the aggregate default rate. This reflects that the large default-increasing effect among (the relatively small measure of) non-mature firms dominates after a rise, while the pretty large default-increasing effect among (the large measure of) mature firms dominates after a cut. In the longer run, moving to higher (lower) rates tends to reduce (rise) aggregate leverage and aggregate default. 


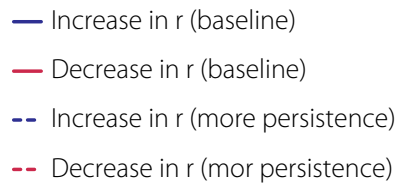

1.5

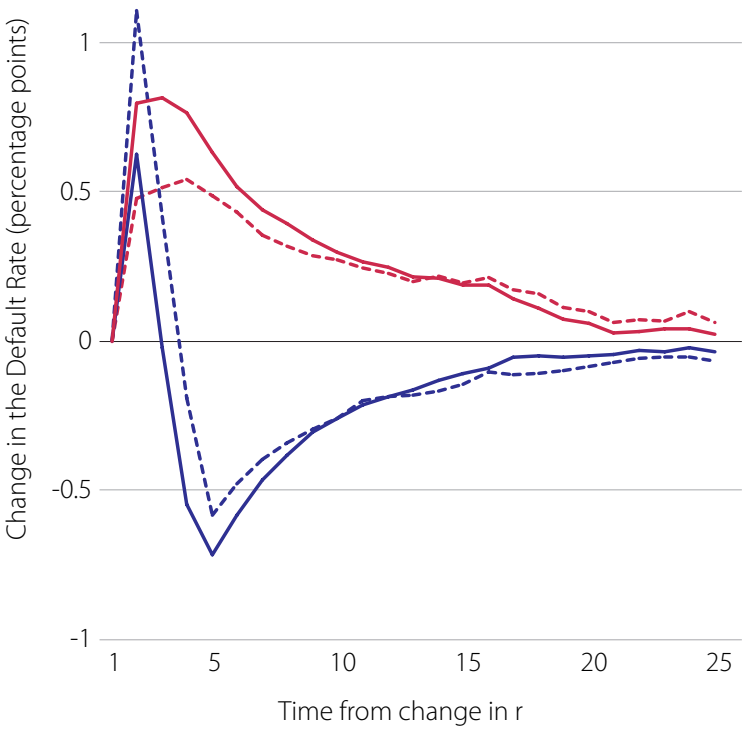

— Increase in $r$ (baseline)

— Decrease in $r$ (baseline)

-- Increase in r (smaller shifts)

-- Decrease in $r$ (smaller shifts)

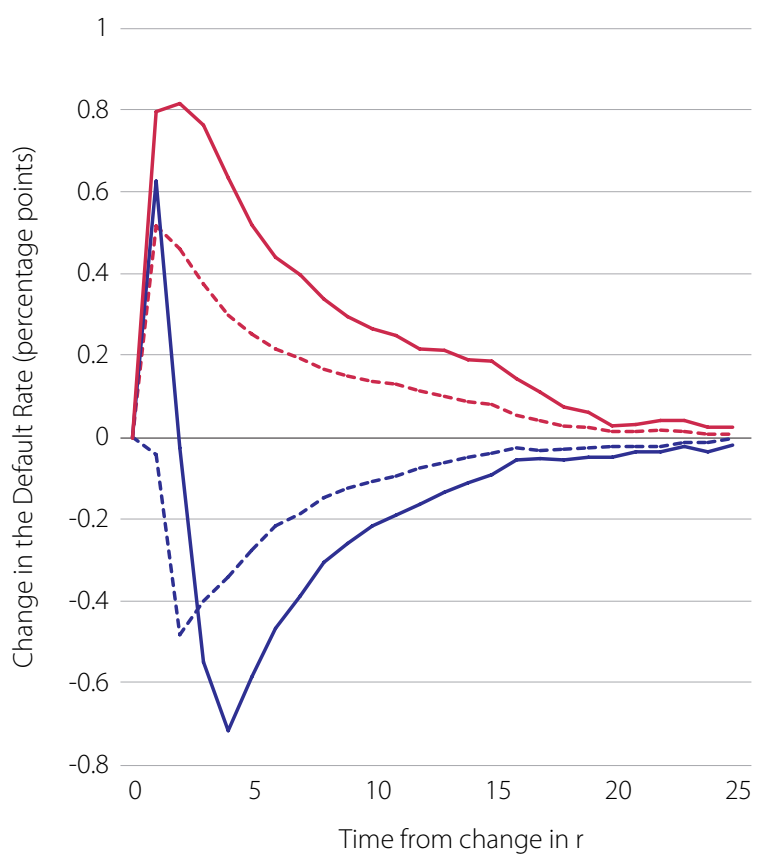

Finally, in order to better understand the effects of aggregate uncertainty, we solve the model and recompute the effects of interest rate shifts under two alternative parameterizations of the Markov chain followed by the risk-free interest rate. The two panels in Figure 7 compare the effects described in Figure 5 for our baseline parameterization with those obtained in each of the alternative scenarios. In the left panel, the alternative process features larger state persistence (we increase $\pi_{L L}=\pi_{H H}$ from 0.9293 to 0.95 ), while in the right panel it features smaller differences between the high and the low interest rate (we increase the low rate to $1 \%$ and reduce the high rate to $2.65 \%$, preserving the unconditional mean). Interestingly, the higher persistence of each phase (which might correspond to the empirical situations in which interest rates are kept "too low for too long"), exacerbates the default-increasing effect of interest rates rises in the shortest term, while it dampens the defaultincreasing effects of interest rate cuts --possibly because the decrease (increase) in firms' continuation value after the shift in the interest rate is larger if rates are expected to remain high (low) for a longer period. As for the right panel, reducing the amplitude of interest rates swings reduces the size of both the short and long run effects of each change. In fact, under the alternative parameterization, the aggregate default-increasing effect of interest rate rises disappears. 



\section{Macroprudential implications}

If we think of reference risk-free interest rates, possibly affected by monetary policy, as a key determinant of what the model describes as $r_{t}$-financiers' opportunity cost of funds- then our results have important implications for some recent macroprudential discussions. In general terms, they provide a call for caution against conclusions reached in static models, in models without firm heterogeneity, in the linear models used in most empirical studies, and whenever the empirical data contains relatively limited exogenous variation in the empirical counterpart of $r_{t}$. It says that the relationship between interest rates, corporate leverage, and credit risk is not simple.

According to our analytical results, lower interest rates imply larger target leverage but may or may not lead to lower default rates. Lower rates make the lending to the highest-levered (or youngest) firms safer because they reduce these firms' effective debt burden, but they may make mature firms riskier, since mature firms will go for higher leverage. Indeed this effect occurs in the parameterization of the model that we have explored, where the aggregate default rate is on average higher when the interest rate is lower. So our numerical results are consistent with the observation that having interest rates too low for too long may imply larger "risk taking" (Borio and $\mathrm{Zhu}, 2008$ ). However, we also find that interest rate rises will tend to produce a temporary rise in default rates, which means that the macroprudential use of monetary policy (e.g. if authorities care about negative externalities caused by high default rates) must be cautious.

Finally, in a model like ours, absent negative externalities associated with a higher default rate, the equilibrium levels of leverage and default (sometimes interpreted as proxies of financiers' "risk-taking", especially when they are banks) cannot be properly deemed excessive from a normative, second-best perspective -i.e. there would be no welfare gains from constraining entrepreneurs' leverage decisions. ${ }^{31}$ Moreover, in our model, these proxies for "risk taking" tend to be larger when $r_{t}$ is lower, but the model per se provides no rationale to advocate keeping interest rates artificially high so as to induce lower leverage and lower default rates. This means that extracting normative macroprudential prescriptions would require identifying and quantifying negative externalities associated with the equilibrium levels of leverage and default produced by a model like ours.

31 As in other models with financial constraints (e.g. Lorenzoni, 2008), aggregate welfare measures may increase using redistributive policies that reduce the constraints of the agents for which they are more binding. In this economy, one such policy might consist of subsidizing the young entrepreneurs to speed up their convergence to target leverage. But more than constraining their leverage, this policy would consist on transferring them funds that they would find in their best interest to use to reduce their leverage. 



\section{Conclusions}

Monetary policies leading to a long period of (too) low interest rates have been mentioned as a possible factor contributing to the genesis of the Great Recession of 2008-2009. Wondering about possible theoretical underpinnings of such a view, this paper develops a dynamic corporate financing model with the explicit goal of examining the impact of shifts in the risk-free interest rate on corporate leverage and credit risk. Firms' financing problem is affected by two key frictions: a moral hazard between entrepreneurs and their outside financiers and entrepreneurial wealth constraints. Interest rates enter the problem by determining outside financiers' opportunity costs of funds. The endogenous link between leverage and default risk comes from the lower incentives of overindebted entrepreneurs to guarantee the survival of their firms.

Firms start up with leverage typically higher than some state-contingent target leverage ratio, and adjust gradually to it through earnings retention. The dynamic response of leverage and default to cut and rises in interest rates is both asymmetric (since it is easier to adjust to a higher target leverage than to a lower one) and heterogeneously distributed across firms (since interest rates affect the burden of outstanding leverage, which differs across firms). We find that both interest rate rises and interest rate cuts may increase the aggregate default rate in the short-run. Instead, higher rates produce lower default rates in the longer run since they induce lower target leverage across all firms. These results help rationalize some of the empirical evidence regarding the so-called risk-taking channel of monetary policy and are relevant to current discussions on the potential macroprudential role of monetary policy. 



\section{Appendix}

\section{Proof of Lemma 1}

The domain of the value function is made of the values of $R$ for which (1) has a solution. If (1) does not have a solution, the firm gets liquidated and pays a final dividend of zero. We could extend the definition of the value function for these values of $R$ by making $v(R)=0$ but in this extended domain the function is constant rather than strictly increasing. So we will constrain attention to the domain in which refinancing is feasible. Hence, consider any two values of the state variable, $R_{1}$ and $R_{2}$ with $R_{1}<R_{2}$ for which (1) has a solution and denote the optimal decisions made under $R_{i}$ as $\left(p_{i^{\prime}}, b_{i}, R_{i}^{\prime}\right)$. Notice that if $\left(p_{2^{2}}, b_{2}, R_{2}^{\prime}\right)$ is a feasible solution under $R_{2^{\prime}}$ then it is also a feasible solution under $R_{1}$, since the only effect of $R_{1}<R_{2}$ on the constraints is to make (4) less stringent. However, the value of the objective function under $R_{1}$ when evaluated at the solution $\left(p_{2}, b_{2}, R_{2}^{\prime}\right)$ together with the definition of $v\left(R_{1}\right)$ implies:

$$
v\left(R_{1}\right) \geq\left(y+b_{2}-R_{1}\right)+\beta\left[u\left(p_{2}\right)+p v\left(R_{2}^{\prime}\right)\right]=\left(R_{2}-R_{1}\right)+v\left(R_{2}\right)>v\left(R_{2}\right),
$$

which proves the result.

\section{Proof of Proposition 1}

The Lagrangian of this problem is:

$$
\mathcal{L}=y+B\left(R^{\prime}\right)-R+\beta\left[u\left(P\left(R^{\prime}\right)\right)+P\left(R^{\prime}\right) v\left(R^{\prime}\right)\right]+\lambda\left[y+B\left(R^{\prime}\right)-R\right]
$$

where $\lambda \geq 0$ is the Lagrange multiplier associated to the inequality constraint. By Kuhn-Tucker conditions, the constraint may or may not be binding. If (9) is not binding, then $\lambda=0$ and the solution for $R^{\prime}$ satisfies the following FOC:

$$
B^{\prime}\left(R^{\prime}\right)+\beta\left\{\left[u^{\prime}\left(P\left(R^{\prime}\right)\right)+v\left(R^{\prime}\right)\right] P^{\prime}\left(R^{\prime}\right)+P\left(R^{\prime}\right) v^{\prime}\left(R^{\prime}\right)\right\}=B^{\prime}\left(R^{\prime}\right)+\beta P\left(R^{\prime}\right) v^{\prime}\left(R^{\prime}\right)=0,
$$

where we have used the fact that $\left[u^{\prime}\left(P\left(R^{\prime}\right)\right)+v\left(R^{\prime}\right)\right]=0$ by (5). Interestingly, (16) does not involve $R$, so it yields the same unconstrained solution $R^{\prime}=R^{*}$ for all the values of $R$ in which (9) can be satisfied, that is, for all $R \leq \bar{R} \equiv y+B\left(R^{*}\right)$. Notice that in (16) the fact that $v^{\prime}\left(R^{\prime}\right)<0$ for all $R^{\prime}$ implies that $B^{\prime}\left(R^{*}\right)>0$ which means (as advanced above) that $R^{*}$ must be in an upward sloping section of $B\left(R^{\prime}\right)$ and we must have $R^{*} \leq \overline{\bar{R}}$

For $R>\bar{R}$, (9) is binding, then $\lambda \geq 0$ and the solution involves choosing the lowest $R^{\prime}$ $>R^{*}$ that satisfies $B\left(R^{\prime}\right)=R-y$. Thus, this solution must also be in the upward slop- 
ing section of $B\left(R^{\prime}\right)$. With a single-peaked $B\left(R^{\prime}\right)$ the inverse of its upward sloping section is well defined, so with slight abuse of notation we can describe the candidate solution as $R^{\prime}=B^{-1}(R-y)$. The existence of this candidate solution requires $B^{-1}(R-y) \leq \overline{\bar{R}}$, i.e. $R \leq y+B(\overline{\bar{R}})$.

The remaining statements contained in the proposition can be immediately derived from these results.

\section{Proof of Proposition 3}

The results stated in this proposition come from the comparative statics (total differentiation) of a reduced system of equations in $R^{*}$ and $p^{*}$ and the exogenous parameters which describes the steady state. To obtain such a reduced system, consider first the first order condition (16) satisfied by $R^{*}$ :

$$
B^{\prime}\left(R^{*}\right)-\beta P\left(R^{*}\right)=0 \text {. }
$$

We want to find out a compact expression of $B^{\prime}\left(R^{*}\right)$.

Particularizing (6) and (5), we have

$$
B\left(R^{*}\right)=\frac{1}{1+r}\left[L+P\left(R^{*}\right)\left(R^{*}-L\right)\right],
$$

and

$$
u^{\prime}\left(P\left(R^{*}\right)\right)+v\left(R^{*}\right)=0 .
$$

It directly follows from deriving in (18) with respect to $R^{*}$ that

$$
B^{\prime}\left(R^{*}\right)=\frac{1}{1+r}\left[P\left(R^{*}\right)+P^{\prime}\left(R^{*}\right)\left(R^{*}-L\right)\right] .
$$

On the other hand, deriving in (19) with respect to $R^{*}$ we have:

$$
u^{\prime \prime}\left(P\left(R^{*}\right)\right) P^{\prime}\left(R^{*}\right)+v^{\prime}\left(R^{*}\right)=0 .
$$

But applying the Envelop Theorem on (8) for $R=R^{*}$ and taking into account that the constraint of the stage problem is not binding at that point makes it obvious that $\nu^{\prime}\left(R^{*}\right)=-1$, so we can write

$$
P^{\prime}\left(R^{*}\right)=\frac{1}{u^{\prime \prime}\left(P\left(R^{*}\right)\right)},
$$

which substituted into $(20)$ yields

$$
B^{\prime}\left(R^{*}\right)=\frac{1}{1+r}\left[P\left(R^{*}\right)+\frac{1}{u^{\prime \prime}\left(P\left(R^{*}\right)\right)}\left(R^{*}-L\right)\right],
$$

which plugged into equation (FOC-uncons2) and, after some reordering, allows us to write such equation as:

$$
[1-\beta(1+r)] P\left(R^{*}\right)+\frac{1}{u^{\prime \prime}\left(P\left(R^{*}\right)\right)}\left(R^{*}-L\right)=0 .
$$


Since $\beta(1+r)<1$ and $u^{\prime \prime}(\cdot)<0$, satisfying this condition requires $R^{*}>L$, which means that the firm will default on its repayment obligation when it fails. The probability of failure is $1-p^{*}$, which is strictly positive under our assumption that $\lim _{p \rightarrow 1}\left|u^{\prime}(p)\right|$ is sufficiently large.

Now, using the notation $v^{*}=v\left(R^{*}\right), p^{*}=P\left(R^{*}\right)$, and $b^{*}=B\left(R^{*}\right)$, we can characterize the steady state as the solution to the system of the following four equations with four unknowns (namely $p^{*}, b^{*}, R^{*}$ and $v^{*}$ ):

$$
\begin{gathered}
v^{*}=y+b^{*}-R^{*}+\beta\left[u\left(p^{*}\right)+p^{*} v^{*}\right], \\
-[1-\beta(1+r)] p^{*} u^{\prime \prime}\left(p^{*}\right)-\left(R^{*}-L\right)=0, \\
b^{*}=\frac{1}{1+r}\left[L+p^{*}\left(R^{*}-L\right)\right], \\
u^{\prime}\left(p^{*}\right)+v^{*}=0 .
\end{gathered}
$$

In this system, (22), (23), (24), and (25) are the counterparts of (1), (21), (18), and (19), respectively.

Finally, using (24) to substitute for $b^{*}$ in (22), and (25) to also substitute for $v^{*}$ in (22), the system simplifies to:

$$
\begin{aligned}
H_{1}\left(p^{*}, \quad R^{*} ; \quad \beta,\right. & r, \quad y, \quad L) \equiv-\left(1-\beta p^{*}\right) u^{\prime}\left(p^{*}\right)-y+\left(1-\frac{p^{*}}{1+r}\right) R^{*}-\frac{1-p^{*}}{1+r} L-\beta u\left(p^{*}\right)=0 \\
+\quad+\quad-\quad+ & -
\end{aligned}
$$

where the only unknowns are $p^{*}$ and $R^{*}$, and the signs below each of the arguments of the functions $H_{1}$ and $H_{2}$ indicate the sign of the corresponding partial derivative. The remaining results in the proposition come from fully differentiating this system with respect to $p^{*}, R^{*}$, and the exogenous parameters. Signing most of the results is immediate. Only a few require some cumbersome algebra that we skip for brevity. To sign some of the partial derivatives, it is important to remember two properties implicit in our formulation: (i) $R^{*}$ is necessarily in the upward slopping section of $B\left(R^{*}\right)$, so we must have $B^{\prime}\left(R^{*}\right) \geq 0$, which implies $-p^{*} u^{\prime \prime}\left(p^{*}\right) \geq\left(R^{*}-L\right)$, (ii) the (iso-elastic) form of $u(\cdot)$ adopted in (eq:privateenefit) satisfies $-p u^{\prime \prime \prime}(p) / u^{\prime \prime}(p)=2-\alpha$ and, hence, is smaller than 1 for all $\alpha>1$.

\section{Proof of Proposition 4}

The results stated in this proposition come from the comparative statics (total differentiation) of a reduced system of equations that, for each given value of $R>\bar{R}$, gives the value $R^{\prime}=B^{-1}(R-y)$ that describes the upward slopping section of the phase diagram depicted in Figure 1, as well as the continuation probability $p=P\left(R^{\prime}\right)$ associated with that constrained level of leverage. Going back to the definitions of $B\left(R^{\prime}\right)$ and $P\left(R^{\prime}\right)$ in terms of more fundamental ingredients of the model, it is con- 
venient to think of the relevant $p$ and $R^{\prime}$ as determined by the system of three equations with three unknowns (with $b=B\left(R^{\prime}\right)$ as the third unknown) given by the binding constraints of the original optimization problem in (1):

$$
\begin{gathered}
u^{\prime}(p)+v\left(R^{\prime}\right)=0, \\
L+p(R-L)-(1+r) b=0, \\
y+b-R=0,
\end{gathered}
$$

where (26) is (2) written as in (5), (27) corresponds to (3), and (28) is the binding version of (4). Clearly we can use (28) to substitute for $b$ in (27), and arrive to a twoequation system that can be written as:

$$
\begin{gathered}
J_{1}\left(p, \quad R^{\prime} ; \quad \beta, \quad r, \quad y, \quad L\right) \equiv u^{\prime}(p)+V\left(R^{\prime} ; \quad \beta, \quad r, \quad y, \quad L\right)=0, \\
-\quad+\quad+\quad-\quad+\quad+\quad-\quad+-++ \\
J_{2}\left(p, \quad R^{\prime} ; \quad R, \quad r, \quad y, \quad L\right) \equiv L+p(R-L)-(1+r)(R-y)=0, \\
+\quad+\quad-\quad-\quad+\quad+
\end{gathered}
$$

where we have written $v\left(R^{\prime}\right)=V\left(R^{\prime} ; \beta, y, L, r\right)$ to make clear that the continuation value of the firm, as determined by the Bellman equation (1) is a function of the state variable as well as all the underlying parameters. The signs below each of the arguments of the functions $J_{1}$ and $J_{2}$ indicate the sign of the corresponding partial derivatives, most of which are immediate to obtain. Notice that the partial derivatives of the function $V\left(R^{\prime} ; \beta, y, L, r\right)$ can be obtained using (1), the Envelop Theorem, and the fact that any parameter that tightens a binding constraint will reduce the value resulting from the maximization.

Equations describe two curves and the constrained optimal refinancing decision given $R$ is given by the intersection between them. To obtain the results stated in the proposition, notice that (29) implicitly defines an decreasing relationship between $p$ and $R^{\prime}$ which can be compactly described as

and substituted into (30) to obtain:

$$
p=P\left(R^{\prime} ; \beta, \quad r, \quad y, L\right),
$$

$$
\begin{aligned}
& K\left(R^{\prime} ; \quad \beta, \quad R, \quad r, \quad y, \quad L\right) \equiv J_{2}\left(P\left(R^{\prime} ; \beta, r, y, L\right), R^{\prime} ; R, r, y, L\right)=0 . \\
& ++-\quad++
\end{aligned}
$$

The signs of the partial derivatives shown in (32) can be determined using the fact that having a strictly increasing relationship between $R$ and $R^{\prime}$ as in the phase diagram in Figure 1 (or, equivalently, having $R^{\prime}$ in the upward slopping section of $B\left(R^{\prime}\right)$ ) necessarily requires

$$
\frac{\partial J_{2}}{\partial p} \frac{\partial P}{\partial R^{\prime}}+\frac{\partial J_{2}}{\partial R^{\prime}}>0
$$

Intuitively, this condition implies that relevant intersection between the two downward slopping relationships described by (29) and (30) always occurs at a point in 
which the curve associated with (30) is stepper than the curve described by (29), and this happens to help signing all the comparative static results in an unambiguous manner. The results for $R^{\prime}$ come directly from (32), while those for the default probability $1-p$ come from combining the direct effects shown in (31) with those channeled through $R^{\prime}$, which if anything reinforce the direct ones.

Finally notice that the statement that $R^{\prime}>L$ stems from the fact that, for $R>\bar{R}$ we have $R^{\prime}>R^{*}$ and we have already proved in Proposition 3 that $R^{*}>L$. Similarly, we have $1-p\left(R^{\prime}\right)>1-p\left(R^{*}\right)$ and we have already established in Proposition 3 that $1-p\left(R^{*}\right)>0$. 



\section{References}

Adrian, T. and Shin, H. (2009). Financial intermediaries and monetary economics. Federal Reserve Bank of New York Staff Reports No. 398.

Altunbas, Y., Gambacorta, L. and Marqués-Ibáñez, D. (2009). An Empirical Assessment of the Risk-taking Channel. Paper presented at the BIS/ECB Conference on Monetary Policy and Financial Stability, 10-11 September.

Audretsch, D. B. (1991). "New-Firm Survival and the Technological Regime”. Review of Economics and Statistics, 73, pp. 441-50.

Bernanke, B., Gertler, M. and Gilchrist, S. (1999). "The Financial Accelerator in a Quantitative Business Cycle Framework". John Taylor and Michael Woodford, eds., Handbook of Macroeconomics, Elsevier, Chapter 21, pp. 1341-1393.

Blume, M. E., Lim, F. and Mackinlay, A. C. (1998). "The Declining Credit Quality of U.S. Corporate Debt: Myth or Reality?". Journal of Finance, 53, pp. 1389-1413.

Bolton, P. and Freixas, X. (2006). "Corporate Finance and the Monetary Transmission Mechanism”. Review of Financial Studies, 19, pp. 829-870.

Borio, C. and Zhu, H. (2008). "Capital Regulation, Risk-Taking and Monetary Policy: a Missing Link in the Transmission Mechanism?”. BIS Working Paper No. 268.

Carlstrom, Ch. and Fuerst, T. (1997). "Agency Costs, Net Worth and Business Fluctuations: A Computable General Equilibrium Analysis". American Economic Review, 87, pp. 893-910.

Clementi, G. L. and Hopenhayn, H. A. (2006). "A Theory of Financing Constraints and Firm Dynamics”. Quarterly Journal of Economics, 121, pp. 229-265.

Cooley, T. F. and Quadrini, V. (2001). "Financial Markets and Firm Dynamics". American Economic Review, 91, pp. 1286-1310.

Cooley, T. F. and Quadrini, V. (2006). "Monetary Policy and the Financial Decisions of Firms". Economic Theory, 27, pp. 243-270.

Cover, J. P. (1992). "Asymmetric Effects of Positive and Negative Money-Supply Shocks”. Quarterly Journal of Economics, 107, pp. 1261-82.

DeMarzo, P. M. and Fishman, M. J. (2007). “Optimal Long-Term Financial Contracting”. Review of Financial Studies, 20, pp. 2079-2128. 
Dyck, A. and Zingales, L. (2004). "Private Benefits of Control: An International Comparison". Journal of Finance, 59, pp. 537-600.

Evans, D. S. (1987). "Tests of Alternative Theories of Firm Growth". Journal of Political Economy, 95, pp. 657-74.

Gertler, M. and Kiyotaki, N. (2010). "Financial Intermediation and Credit Policy in Business Cycle Analysis". Manuscript prepared for the Handbook of Monetary Economics.

Hackbarth, D., Miao, J. and Morellec, E. (2006). "Capital Structure, Credit Risk, and Macroeconomic Conditions". Journal of Financial Economics, 82, pp. 519-550.

Hamilton, J. D. (1989). "Analysis of Nonstationary Time Series and the Business Cycle”. Econometrica, 57, pp. 357-384.

Hennessy, C. A. and Whited, T. M. (2005). "Debt Dynamics". Journal of Finance, 60, pp. 1129-1165.

Holmstrom, B. and Tirole, J. (1997). "Financial Intermediation, Loanable Funds, and the Real Sector". Quarterly Journal of Economics, 112, pp. 663-91.

Ioannidou, V. P., Ongena, S. and Peydró, J. L. (2010). "Monetary Policy, Risk-Taking and Pricing: Evidence from a Quasi Natural Experiment”. ECB, mimeo.

Jacobson, T., Kindell, R., Linde, J. and Roszbach, K. F. (2008). Firm Default and Aggregate Fluctuations. CEPR Discussion Papers 7083.

Jiménez, G., Ongena, S., Peydró, J. L. and Saurina, J. (2010). “Hazardous Times for Monetary Policy: What do Twenty-Three Million Bank Loans Say About the Effects of Monetary Policy on Credit Risk?". ECB, mimeo.

Kiyotaki, N. and Moore, J. (1997). "Credit Cycles". Journal of Political Economy, 105, pp. 211-248.

Landier, A., Sraer, D. and Thesmar, D. (2010). "Going for Broke: New Century Financial Corporation, 2004-2006”. Toulouse School of Economics, mimeo.

Lorenzoni, G. (2008). "Inefficient Credit Booms”. Review of Economic Studies, 75, pp. 809-833.

Maddaloni, A. and Peydró, J. L. (2010). Bank Risk-Taking, Securitization, Supervision and Low Interest Rates Evidence from the Euro Area and the U.S. Lending Standards. ECB Working Paper 1248.

Mankiw, G. (1986). "The Allocation of Credit and Financial Collapse”. Quarterly Journal of Economics, 101, pp. 455-470.

Morellec, E., Nikolov, B. and Schurhoff, N. (2008). "Dynamic Capital Structure under Management Entrenchment: Evidence from a Structural Estimation”. Mimeo, Swiss Finance Institute. 
Rajan, R. G. (2005). Has Financial Development Made the World Riskier? NBER Working Paper 11728.

Repullo, R. and Suárez, J. (2000). "Entrepreneurial Moral Hazard and Bank Monitoring: A Model of the Credit Channel”. European Economic Review, 44, pp. 1931-1950.

Shleifer, A. and Vishny, R. W. (2010). "Unstable Banking". Journal of Financial Economics, 97, pp. 306-318.

Stiglitz, J. E. and Weiss, A. (1981). "Credit Rationing in Markets with Imperfect Information”. American Economic Review, 71, pp. 393-410.

Weise, C. L. (1999). "The Asymmetric Effects of Monetary Policy: A Nonlinear Vector Autoregression Approach". Journal of Money, Credit, and Banking, 31, pp. 85-108.

Williamson, S. D. (1987). "Costly Monitoring, Loan Contracts, and Equilibrium Credit Rationing”. Quarterly Journal of Economics, 102, pp. 135-146. 


